\title{
DO NEIGHBORHOODS GENERATE FEAR OF CRIME? : AN EMPIRICAL TEST USING THE BRITISH CRIME SURVEY
}

IAN BRUNTON-SMITH, Department of Sociology, University of Surrey

AND PATRICK STURGIS, Division of Social Statistics, University of Southampton

This research was conducted with support from an ESRC CASE award in collaboration with the UK

Home Office (Grant number: PTA-033-2005-00028). We gratefully acknowledge the three anonymous reviewers, whose comments and suggestions improved an earlier version of this paper. 


\section{DO NEIGHBORHOODS GENERATE FEAR OF CRIME? : AN EMPIRICAL TEST USING THE BRITISH CRIME SURVEY}

Criminologists have long contended that neighborhoods are important determinants of how individuals perceive their risk of criminal victimization. Yet, despite the theoretical importance and policy-relevance of these claims, the empirical evidence-base is surprisingly thin and inconsistent. Drawing on data from a national probability sample of individuals, linked to independent measures of neighborhood demographic characteristics, visual signs of physical disorder, and reported crime, we test four hypotheses about the mechanisms through which neighborhoods influence fear of crime. Our large sample size, analytical approach and the independence of our empirical measures enable us to overcome some of the limitations that have hampered much previous research into this question. We find that neighborhood structural characteristics, visual signs of disorder, and recorded crime all have direct and independent effects on individual level fear of crime. Additionally, we demonstrate that individual differences in fear of crime are strongly moderated by neighborhood socio-economic characteristics; between group differences in expressed fear of crime are both exacerbated and ameliorated by the characteristics of the areas in which people live.

Key words: Fear, criminal victimization, multilevel, neighborhood effects

Ian Brunton-Smith is a lecturer in the Department of Sociology at the University of Surrey. His research interests include criminal statistics, neighborhood effects, missing data problems, and survey methodology.

Patrick Sturgis is Professor of Research Methodology and Director of the National Centre for Research Methods at the University of Southampton. His research interests are in the areas of survey methodology, statistical methods, public opinion, and political behaviour. 


\section{INTRODUCTION}

Over the past forty years and more, citizen fear of criminal victimization has become a central area of criminological investigation and debate, as well as a key focus of crime policy throughout the world. Empirical analyses of the causes and consequences of 'fear of crime' have tended to concentrate, often in a rather atheoretical manner, on the characteristics of individuals and groups who express higher levels of fear in surveys (Hale, 1996). For instance, researchers have pointed to the importance of 'vulnerability' as a function of socio-demographic characteristics such as age, gender, and social class as a key driver of fear at the individual level (Killias, 1990; Skogan and Maxfield, 1981). Others have noted the higher prevalence of fear amongst those with direct and indirect victimization experience (Box, Hale and Pack, 1987; Skogan, 1987) and the 'agenda-setting' function of the media (Chiricos, Eschholz and Gertz, 1997; Gerbner and Gross, 1976; Liska and Baccaglini, 1990).

In contrast, a second, more sociological tradition, has emphasized the importance of the wider social context in which individuals are situated for understanding their perceptions of risk (Girling, Loader and Sparks, 2000; Hale, Pack and Salked, 1994; Hollway and Jefferson, 1997; Jackson, 2006). To properly understand individual variability in fear of crime, the argument goes, we must incorporate the influence of local community characteristics and neighborhood level social processes. In particular, scholars drawing on the role of 'social disorganization' in undermining community-level informal social control mechanisms have emphasized the influence of social-structural characteristics and visible signs of neighborhood disorder in informing residents of potential victimization risks (Box, Hale and Andrews, 1988; Ferraro, 1995; Hale, Pack and Salked, 1994; Jackson, 2004; McGarrell, Giacomazzi and Thurman, 1997; Skogan, 1990; Taylor, 2001; Wilson and Kelling, 1982). It is these latter ideas that motivate the analyses in this paper. For, despite their commonsense appeal and widespread currency within criminology and policy-making circles, empirical evidence for independent, neighborhood-level causal influences in generating fear of criminal victimization is both weak and inconsistent. We contend that the failure to find consistent corroborating evidence of 'neighborhood effects' is, at least in part, methodological in nature. Early investigations into the role of neighborhoods were hindered by a lack of 
robust neighborhood level data and a reliance on inappropriate analytical strategies, in particular, treating geographically-clustered sample designs as if they were simple random samples (see for example Box, Hale and Andrews, 1988; Hough, 1995; Skogan and Maxfield, 1981). Only more recently have scholars begun to overcome such methodological limitations, with a growing number of studies adopting a 'multilevel' framework, in which neighborhood level data is used to situate individual respondents within specific local contexts (Fitzgerald, 2008; Miethe and Mcdowall, 1993; Morenoff, Sampson and Raudenbush, 2001; Robinson et al., 2003; Sampson, Raudenbush and Earls, 1997; Snell, 2001; Taylor, 2001; Wilcox, Quisenberry and Jones, 2003; Wilcox-Rountree, 1998; Wilcox-Rountree and Land, 1996; Wyant, 2008). Yet, while these studies have certainly advanced our understanding of the role of local areas in generating crime-related anxiety, they have generally been based on small samples and/or have covered a limited number of neighborhoods from single metropolitan areas, usually in the United States. They have also tended to test the proposed neighborhood-level fear generating mechanisms in isolation from one another rather than jointly, and to rely on measures of neighborhood characteristics which are elicited from the same survey respondents that are used to generate individual level fear of crime indicators. These methodological limitations mean that there remain important ambiguities about whether and how neighborhood characteristics influence the crime-related risk perceptions of individual residents.

Our aim in this paper is to add clarity to this field of investigation by carefully enunciating the causal pathways through which neighborhoods are thought to influence individual fear of crime and to test these hypothesized mechanisms simultaneously, using high quality data and appropriate analytical methods. We use British Crime Survey (BCS) data from 2002-2005 which we attach to a new neighborhood geography created in 2001 by the UK Office for National Statistics. Neighborhood identifiers are then linked to police records and data from the 2001 UK decennial census which, when aggregated, provide independent measures of recorded crime rates and the social and organizational characteristics of neighborhoods. We also employ independent measures of visual signs of neighborhood disorder, which are derived from survey interviewer ratings rather than respondent assessments. This leaves us with a data set combining a sample of 102,133 individual records with detailed contextual data 
from some 5,196 neighborhoods, allowing us to carry out robust tests of the postulated ecological drivers of fear of criminal victimization in the British context. Importantly, the BCS is a nationally representative survey, so we are able to examine neighborhood effects across the full national distribution of neighborhoods in and around a range of different urban, rural, and metropolitan contexts.

To foreshadow our results, we find that when tested simultaneously, recorded crime, neighborhood structural characteristics and visual signs of disorder all exert direct and independent effects on the expressed fear of crime of residents. Additionally, we demonstrate that neighborhoods shape crime-related fear in more subtle ways too, by moderating the effects of its individual level causes. For example, we show that the degree of fear expressed by both majority and minority ethnic groups varies systematically as a function of the ethnic diversity of the neighbourhood in which they live. The paper proceeds in the following manner. First, we review the existing theoretical and empirical literature relating to neighborhood influences on individual fear of crime. This leads us to specify four key causal mechanisms through which neighborhoods influence individual crime-related risk perceptions. We then describe in detail the data that forms the basis of our analysis and the modeling strategy to be undertaken, before presenting the results of our statistical models. We conclude with a consideration of the implications of our findings for our understanding of neighborhood-level influences on citizen perceptions of crime risk.

\section{HOW DO NEIGHBORHOODS INFLUENCE FEAR OF CRIMINAL VICTIMISATION?}

Research linking individual fear of crime to the wider context of social life is premised on the idea that fear and anxiety about crime are, in part, a product of the wider social environment in which criminal activity occurs (see for example Ferraro, 1995; Hale, Pack and Salked, 1994; and Hollway and Jefferson, 1997). It is this locally embedded feature of crime that is thought to be central to how individuals make sense of their risks of victimization. But what are the actual pathways through which geographical units exert their influence on the individuals who inhabit them? From the existing literature, four principle mechanisms through which neighborhoods influence fear can be identified: 1. through 'rational' 
responses to variability across neighborhoods in the actual incidence of crime 2 . through the social and organizational characteristics of neighborhoods which promote or inhibit collective efficacy and informal social control 3. through visual signs of disorder in the neighborhood; and, 4. through the moderating effects of neighborhood-level characteristics on the individual level causes of fear.

\section{The Incidence of Crime}

Early studies pointed to the most immediately obvious way in which neighborhoods might influence fear of crime: their social and economic composition influences the rate of offending and the proportion of offender residents which, in turn, shapes assessments of individual risks of victimization in a particular locality (Lawton and Yaffe, 1980; Lewis and Maxfield, 1980; Liska, Lawrence and Sanchiricom, 1982). For instance, materially deprived individuals have, ceteris paribus, greater incentive to obtain resources through illegal activities such as robbery, theft, and fraud. Therefore, the incidence of these types of crimes will be higher in neighborhoods containing higher proportions of economically deprived individuals. If neighborhood residents respond rationally to variation in objective victimization risk, then it is clear that those living in less affluent neighborhoods will express greater fear of experiencing these types of crime than residents living in more salubrious locations. In this view, then, fear is a rational reaction to the objective risk of victimization in the neighborhood in which an individual lives (Hale, 1996; Jackson, 2006).

Despite the commonsense appeal of this account, empirical evidence has not yielded consistent support for a direct link between neighborhood crime rates and survey measures of individual fear. Many studies have found no significant association between fear and the level of crime, leading to speculation that fear of crime is, at least insofar as it is measured in surveys, an 'irrational' response, unrelated to objective risks (Ferraro, 1995; Furstenberg, 1971; Kershaw et al., 2000; Lewis and Salem, 1986; Perkins and Taylor, 1996; Robinson et al., 2003). On the other hand, some studies have found positive (though generally weak) correlations between fear and levels of crime, although these studies are not without limitations. Skogan and Maxfied (1981) provided some of the first evidence that fear of crime might be 
directly related to the levels of crime in the local area whilst controlling for other neighborhood characteristics, although this was based on a measure of the crime rate derived from respondent perceptions of the extent of crime $^{1}$ and failed to include independent controls for the level of disorder (measures of crime derived from survey respondents were also used in the study of Booroah and Carcach, 1997). Using recorded crime data from 26 cities, Liska, Lawrence and Sanchiricom, (1982) demonstrated higher levels of fear in cities with higher recorded crime rates, whilst simultaneously controlling for characteristics of each city. However this was restricted to an aggregate analysis, with no information about individual variability in fear. A similar link between crime rates and fear at the aggregate level was also demonstrated by Markowitz et al. (2001). Some studies utilizing recorded crime data have found a direct link with individual levels of fear of crime whilst controlling for individual and neighborhood differences, but have not incorporated independent assessments of the extent of disorder in the neighborhood (Taylor and Hale, 1986; Wilcox-Rountree and Land, 1996; Wyant, 2008).

In our assessment, the most convincing evidence of a link between the objective risk of victimization and fear to date is to be found in the work of Taylor (2001). In a study of the city of Baltimore, he identified a weak but significant relationship between fear of crime and the recorded burglary rate within a local area, after controlling for independently assessed signs of disorder and for structural characteristics of the neighborhood. However, despite the quality of the evidence provided from this study, the robustness and generality of the finding is open to question as a result of its focus on a single metropolitan area in the United States.

\section{Neighborhood Social and Organizational Structures}

A second important route through which neighborhoods are thought to leverage fear of crime is via the social, economic, and structural characteristics of the built environment that have been shown to be

\footnotetext{
${ }^{1}$ Skogan and Maxfield (1981) did offer some indication that fear might be linked to police recorded crime rates, however this was restricted to a bivariate assessment
} 
important modulators of low level disorder and criminal behavior. Particularly important in this regard is the seminal work of Shaw and McKay (1942), who pointed to the role of social disorganization in generating, or at least failing to inhibit, antisocial and criminal behavior. Referring to those aspects of local communities that serve to militate against informal social control of deviant behavior, Shaw and McKay proposed three structural dimensions of neighborhoods that, they argued, are of central importance to explaining variation in crime: the socio-economic status of the area; the level of residential mobility; and the degree of ethnic heterogeneity. Specifically, they linked rapid population change within low socio-economic status and ethnically diverse neighborhoods to a breakdown of formal and informal organizational protocols. This breakdown limits the ability of communities to control the behavior of both residents and outsiders, prompting increased delinquency and other forms of normatively deviant behavior. Also key in this regard is the innovative work of Robert Sampson and colleagues (Morenoff, Sampson and Raudenbush, 2001; Sampson and Raudenbush, 1999; Sampson, Raudenbush and Earls, 1997). In a seminal series of studies, these scholars have demonstrated that the social and organizational characteristics of neighborhoods can undermine collective efficacy which, in turn, results in a higher incidence of neighborhood disorder and criminal activity. Additionally, this work has shown that neighborhood structural characteristics, particularly racial composition, act as signifiers of deficient social control mechanisms, which serve to magnify and distort subjective perceptions of the prevalence of social and physical disorder (Sampson, 2009; Sampson and Raudenbush, 2004). Neighborhood social-structural characteristics are thought, therefore, to affect fear of crime both indirectly through their influence on criminality and disorder in the neighborhood but also directly, as signifiers of deficient mechanisms of social control and weak or fragile feelings of efficacy within the local community.

In contrast to the effect of recorded crime, existing research provides more consistent support for the effect of neighborhood social and organizational characteristics on fear. Scholars have identified significantly higher levels of fear in inner-city areas when compared with more urban and rural areas (Allen, 2006; Hale, Pack and Salked, 1994); and with higher population density (Bankston et al., 1987). Others have found higher levels of fear amongst people living in neighborhoods with more ethnically 
diverse populations (Kershaw and Tseloni, 2005; Covington and Taylor, 1991); higher levels of population turnover (Krannich, Berry and Greider, 1989; Taylor and Covington, 1993); lower socioeconomic status (Covington and Taylor, 1991; Fitzgerald, 2008; Hale, Pack and Salked, 1994); higher levels of neighborhood change (Taylor and Covington, 1993); large youth populations (Hale, Pack and Salked, 1994); and lower levels of community integration (Lewis, and Salem, 1986; Skogan, 1981; Taylor and Hale, 1986; Wilcox-Rountree and Land, 1996). An important limitation of these studies, however, is that none of them employs simultaneous controls for independently collected measures of crime and disorder, relying on survey responses for one or both of these measures, or failing to include one or other of them altogether. This means that the identified relationships might be spurious in nature, arising out of the endogeneity of the survey responses or the joint dependency of fear and neighborhood characteristics on either of these unobserved variables.

\section{Visible Signs of Disorder}

To argue that neighborhoods influence individual-level fear of crime as a function of the incidence of offenders and the rate of offending in the locality is uncontroversial, in commonsense terms at least. However, a more tendentious claim has frequently been advanced in the criminological literature, to the effect that neighborhood characteristics can influence individual fear, over and above the level of 'objective' risk of victimization in the neighborhood. This idea proposes that visible and emblematic signs of disorder distort perceptions of risk and, consequently, augment expressed fear. The idea was first properly set out by Hunter (1978), who pointed to the malign influence of a range of low level disorders such as vandalism, abandoned buildings, graffiti, noise pollution, unsupervised teenage groups, and litter. These, Hunter proposed, act as important symbols of the extent to which a neighborhood is in decline and is, therefore, unable to exert social control over crime and disorderly behavior. This, in turn, acts as a powerful visual cue to residents of the neighborhood about their risk of victimization.

Crucially, Hunter argued that these signs of disorder can be more important determinants of crime-related fear than the actual incidence of crime in the neighborhood, partly because they are often 
highly visible but also because they are able to capture a much broader range of signals and are thus more informative to busy citizens than official crime statistics (see also Skogan, 1996). In short, this perspective proposes that, although signs of disorder are highly correlated with levels of recorded crime, they are not coterminous. And it is this gap between the symbolic environment and the objective risk that opens the door to neighborhood physical environments exerting direct influences on individual fear of crime, over and above the level of objective risk. Similar arguments about the influence of the symbolic aspect of neighborhood environments have been advanced by a number of different scholars in the intervening years (Innes, 2004; Sampson and Raudenbush, 2004; Skogan and Maxfield, 1981; Taylor, 2001; Wilson and Kelling, 1982; Wyant, 2008), most notably in the form of Wilson and Kelling's (1982) influential 'broken windows' theory, which highlighted the role that un-repaired physical signs of disorder can play in eroding community cohesion and promoting, in turn, further disorder and crime.

The notion that visual signs of neighborhood disorder exert a direct influence on fear of crime has a good deal of prima facie empirical support (Markowitz et al., 2001; Robinson et al., 2003; Taylor, 2001; Wyant, 2008). For example, using three years of data from the BCS aggregated to the neighborhood level, Markowitz et al., (2001) find a strong effect of disorder on fear, which they argue, feeds back into increasing disorder in the neighborhood. Controlling for neighborhood crime rates, they find that the effect of disorder is significantly stronger than that of recorded crime. In a more recent study of 45 neighborhoods in Philadelphia, Wyant (2008) also demonstrated a significant neighborhood level relationship between fear of criminal victimization and perceptions of low level disorder, net of other neighborhood characteristics, which he showed to be mediated through individual perceptions of risk.

Visual signs of neighborhood disorder are, of course, difficult to measure accurately and to integrate with individual survey responses. Such practical hurdles of measurement have led many researchers to rely on the self-reported perceptions of respondents themselves, rather than independently collected evidence of disorder. This strategy, however, leaves open the strong possibility that any observed effect of disorder on fear is endogenous, with fear of crime driving perceptions of disorder rather than (or in addition to) the other way round (Sampson and Raudenbush, 1999; Tseloni, 2007). To 
counter this possibility, some researchers have invested considerable resources in gathering independent measures of disorder through systematic observation of social spaces (Perkins and Taylor, 1996; Sampson, 2009; Sampson and Raudenbush, 2004; Taylor, 2001; Taylor and Covington, 1993) while others have used interviewer assessments of the levels of disorder in the area (Taub, Taylor and Dunham, 1984). However, of these studies, only some have looked specifically at the effect of disorder on fear of crime, with the studies of Sampson and Raudenbush (2004; see also Sampson, 2009) and Taub, Taylor and Dunham, (1984) focusing on the association with crime and disorder in the neighborhood rather than the fear of crime itself. Of the remaining studies, only the work of Taylor (2001) includes an independent measure of the offending rate, finding that visible signs of disorder were largely unrelated to expressed fear after conditioning on this and other neighborhood level characteristics. However, the generality of this finding is open to question given the focus of this study on the effect of graffiti within a single metropolitan area.

\section{Moderating Neighborhood Effects}

In addition to direct effects on fear of crime via their structural characteristics, crime rates, and visual signs of disorder, neighborhoods have also been argued to moderate the effects of individual-level causes of crime. That is to say, the way in which an individual level characteristic shapes assessments of victimization risk might operate differently as a function of the kind of neighborhood in which the individual is situated. For example, although women are, on average, more fearful of crime than men, this population average may vary systematically as a function of the characteristics of individual neighborhoods. The difference in fear between men and women might, for example, be exacerbated in neighborhoods with less public street lighting, or in which the concentration of ethnic minority groups is higher. Pursuing this idea of 'contextual interactions', McGarrell, Giacomazzi and Thurman (1997) showed the magnitude of individual differences in fear of crime to be dependent on the degree of low level disorder within the local area. Distinguishing between low, medium and high disorder neighborhoods, these authors demonstrated that, in the absence of high levels of disorder, individual 
characteristics are highly predictive of fear, but that these differences are considerably weaker in areas where high levels of disorder are apparent. Similarly, looking specifically at fear of burglary, WilcoxRountree and Land (1996) showed the effect of previous victimization experience on fear of crime to be moderated by signs of disorder in the neighborhood, with a significantly weaker effect in areas with higher perceived disorder (see also Wilcox-Rountree, 1998, and Wilcox, Quiseberry and Jones, 2003). Taylor, Schumaker and Gottfredson (1986), on the other hand, found the effect of visible signs of disorder on expressed fear to be moderated by social class, with blue-collar workers more sensitive to such visual cues than either poor or more affluent individuals. While residents of poor neighborhoods were apparently concerned with more immediate and material threats, those in wealthier areas tended to interpret signs of disorder as temporary aberrations or oddities. Only those in blue collar neighborhoods appeared to interpret visual signs of disorder as signaling a potential victimization threat. While all of these studies point to the potential importance of neighborhoods in magnifying or inhibiting the effects of individual level predictors, they all suffer from the by now familiar reliance on self reported perceptions of disorder, meaning we cannot reject the plausible alternative scenario, that it is fear of crime which, to some extent at least, drives perceptions of disorder.

In summary, then, while the theoretical literature has identified four primary mechanisms through which neighborhoods might exert a causal influence on individual fear of crime, the empirical evidence base to date cannot be taken as providing robust and consistent support that they exert independent effects. It is our contention that this on-going ambiguity is, to a large extent, attributable to methodological limitations. First, existing studies have tended to examine these mechanisms in isolation, when any proper test must consider their effects simultaneously. Second, when estimating the effect of neighborhood level characteristics on expressed fear, existing studies have often failed to adequately control for compositional differences between neighborhoods. Because individuals are not randomly allocated to neighborhoods but choose or are constrained to live in particular locales, it is essential to control for differences between neighborhoods in the sorts of individuals who comprise the resident population. Third, in measuring neighborhood level characteristics, there has been an over-reliance on the 
self-reported perceptions of survey respondents, at the expense of independently collected indicators, making inferences about causal order highly problematic. And fourth, the majority of the evidence to date has been based on data from a limited number of neighborhoods from single metropolitan areas, with relatively little consideration of the generalizability of these findings to rural areas or other urban contexts. Our aim in this paper is to add clarity to the debate over the effects of neighborhoods on fear of crime by testing the four proposed mechanisms simultaneously, using a high quality national dataset, with appropriate compositional controls and measures of key causal variables that are collected independently from the survey data used to gauge individual level fear. The four proposed neighborhood mechanisms are specified more formally in the following testable hypotheses:

H1: individual level differences in fear of crime are positively associated with ecological concentrations of (police) recorded crime.

$\mathrm{H}$ 2: individual level differences in fear of crime are positively associated with the degree of independently collected visual signs of disorder in a neighborhood.

H3: individual level differences in fear of crime are negatively associated with cohesive neighborhood social and organizational structures.

H4: the effect of individual level predictors on fear of crime varies as a function of neighborhood social and organizational structures, crime, and independently collected visual signs of neighborhood disorder.

It is essential to note that each of these hypotheses assumes controls for the other three mechanisms, as well as for compositional differences between neighborhoods.

\section{DATA}


We draw our individual-level data from the British Crime Survey, a nationally representative victimization survey of adults aged over 16 living in private residential accommodation in England and Wales. The BCS is widely recognized as a world leader in victimization surveys and following a methodological review in 2001 is now one of the largest social surveys conducted in Britain. The survey uses a multistage, stratified sample design, in which a sample of postcode sectors is drawn with probability proportional to size, and then a sample of 32 households is drawn from within each sector. An individual is then randomly selected from within each household to take part in the survey (for more detail on the sampling procedure, see Bolling, Grant and Donovan, 2008). We use three years of data, covering the period 2002 to 2005 , with response rates of $74.4 \%, 74.1 \%$ and $74.8 \%$ respectively, yielding an analytical sample size of 102,133 over the three years.

\section{Multi-level Modeling}

The multistage sample design of the BCS means that to ensure correct estimates and standard errors, some statistical adjustment is needed to account for the non-independence between observations from the same cluster. However, rather than simply correcting estimates post-hoc, we use this non-independence as a substantively interesting source of information about the neighborhood level influences on individual outcomes. By identifying a clustering variable that represents local neighborhoods, we are able to test our four hypotheses about the mechanisms through which neighborhoods affect fear of crime.

To incorporate this non-independence between observations from the same neighborhood we use a multilevel modeling approach (Goldstein, 2003). This is an extension to regression methods that allows the intercept and coefficient estimates of an individual level model to vary across neighborhoods, enabling a separation of variation resulting from differences between observations within the same neighborhood from that which results from differences between neighborhoods. Consequently, we are able to obtain estimates of the relative contributions of individuals and neighborhoods to total variation in fear of crime, before incorporating neighborhood level measures and 'cross-level interactions' between neighborhood and individual levels measures to account for this variability. 


\section{Defining Neighborhoods}

To represent local neighborhoods we use the middle layer of the newly introduced census Middle Super Output Area geography (MSOA). These are composed of an average of 2,500 households grouped together based on spatial proximity, and homogeneity of dwelling type and tenure. MSOA are small enough to act as a reasonable approximation for the locality of each respondent, and have been designed to be more stable over time and consistent in size than previous area classifications used in the U.K. There was also a consultation stage with local authorities when these boundaries were constructed, ensuring they represent 'meaningful' geographic areas that do not cross clear physical boundaries like major roads or waterways and tying them more closely to the conceptual treatments put forward by community studies (Chaskin, 1998). However, we cannot escape the fact that by relying on fixed boundaries we are adopting a somewhat arbitrary measure of neighborhoods. In reality, residents living towards the edge of these boundaries may also be influenced by adjacent neighborhoods. Similarly, the characteristics or nearby areas will likely be highly correlated because of their spatial proximity, with neighborhoods in closer proximity to one another often sharing similar characteristics, and consequently influencing one another (Lebel et al., 2007).

To account for this increased level of dependency we incorporate an additional, higher level of clustering in our analysis. MSOAs were also designed to be congruous with Crime and Disorder Reduction Partnerships (CDRP). CDRPs are multiagency groups including police, local authorities, probation service, health authorities, the voluntary sector, and local residents and businesses. These partnerships have clearly defined geographic boundaries, allowing us to place neighborhoods within the wider geographic context of the area. This is also of substantive interest to the analysis, as CDRP were specifically intended to "develop and implement strategies to tackle crime and disorder including antisocial and other behavior adversely affecting the local environment" (Crime and Disorder Act, 1998). As such, there is good reason to anticipate that they may have an influence on the fear of crime of residents. Including CDRP as a third level in the model yields data from a total of 5,196 MSOA across England and 
Wales, which are themselves clustered within 353 CDRP. Unfortunately, no complete and reliable data about the characteristics of CDRPs is currently available, so we are not at this stage, able to include predictors at this level of our model.

\section{MEASURES}

Since the concept of fear of crime became a serious focus of survey research in the late 1960s, its appropriate operationalization has been the subject of considerable debate and, although a full consensus has not been reached on its appropriate measurement, it is now clear that fear of crime is multidimensional in nature (Farrall et al., 1997; Ferraro and LaGrange, 1987; Hough, 2004; Skogan, 1981 Ferraro and LaGrange 1987). Skogan (1996) identifies three primary cognitive dimensions that have been the focus of survey measures: concern (to what extent is crime a problem for self and community), risk (beliefs about the probability of victimization) and threat (potential for harm). We use three items from the BCS that combine these three dimensions into a single summary assessment of 'worry' about different types of personal crime and disorder (all items are measured on a four point Likert-scale ranging from 'not at all worried' (1), to 'very worried' (4)):

\section{How worried are you about being mugged or robbed?}

2. How worried are you about being physically attacked by strangers?

3. How worried are you about being insulted or pestered by anybody, while in the street or any other public place?

By combining the distinct cognitive components of fear into a single summary assessment, it is clear that a degree of imprecision and ambiguity is introduced into the interpretation of responses to these items. Nonetheless, on prima facie basis, they appear to incorporate the key cognitive components of the concept in which we are interested and to capture what Hough (2004:175) has referred to as a stable mental state summarizing the "intensity of worry about different crimes". For analysis purposes the items were 
combined into a continuous scale using principal components analysis (mean 0, standard deviation 1, range -1.47 to 2.30 ). The scale has high internal reliability, with all three items displaying component loadings above 0.8 in the PCA model. Multiple group confirmatory factor analysis (Bollen, 1989) confirms the stability of item parameters across survey years, with tests for configural, metric and scalar invariance (Meredith, 1993) all falling well within accepted limits.

To capture variations in the levels of crime between neighborhoods we include a measure of recorded crime in each MSOA taken from the English Indices of Deprivation (Noble et al., 2004). This is derived from police records of the exact location where each offence took place, providing us with a measure of crime rates at a significantly lower spatial scale than in previous studies, covering the local neighborhood immediately surrounding each respondent's home. This makes it possible to more accurately assess whether crime conditions at the very local level influence the amount of fear reported by local residents. Our measure of the crime rate is a composite index from 33 different offences recorded by the police, covering four major crime types that have occurred in the neighborhood between April 2003 and March 2004 (burglary, theft, criminal damage, and violence). For each of the four crime types, the crime rate in each census Super Output Area was calculated (covering approximately 500 homes). These were then standardized, and combined to form a single index measure for each Output Area. ${ }^{2}$ The scores from all areas within the same MSOA were then aggregated to produce an overall measure of recorded crime in each neighbourhood. It has long been recognized that police recorded crime statistics present a limited and fragmentary picture of the true extent of crime, omitting all incidents that are not reported to the police (Skogan, 1996; Brunton-Smith and Allen, 2010). However, the recent introduction of the National Crime Recording Standard across police forces means that whilst recorded crime figures provide a biased picture of the full extent of crime by under-representing less serious offences, it is likely that this

\footnotetext{
${ }^{2}$ The four crime types were combined using weights derived from Maximum Likelihood Factor Analysis, with burglary given a weight of 0.18 , violence 0.25 , theft 0.35 , and criminal damage 0.22 (summing to 1 ). Full details of this procedure are included in Noble et al., (2004).
} 
bias will be constant across neighborhoods, giving us a suitable measure of relative variations in risk (Simmons, Legg and Hosking, 2003; Skogan, 1974). More importantly, because our measure of the offending rate in the neighborhood is not derived from survey respondents but from actual reported incidents, we can reject by design the possibility that our measure of neighborhood crime might itself be influenced by having been embedded within the same measurement procedure as was used for assessing fear of crime.

For our measure of visible signs of neighborhood disorder we use interviewer ratings of the level of three kinds of disorder in the immediate vicinity of the sampled address. Whilst not providing as detailed a picture of the extent of local disorder as systematic social observations conducted by trained observers, Sampson, Morenoff and Gannon-Rowley, (2002: 471) note that these interviewer assessments can provide a more cost-effective and practically feasible alternative that can be implemented on a wider scale than single metropolitan areas. For each sampled address, interviewers were instructed to rate how common litter, vandalism (including graffiti), and run down property are within the area (measured on a 4-point likert scale from 'not at all common' to 'very common'). ${ }^{3}$ These ratings are combined using principal components analysis to form a single index of the visible signs of physical disorder surrounding the respondent's dwelling. ${ }^{4}$ Within each MSOA these component scores are then aggregated to construct an overall measure of the extent of disorder within the neighborhood, with an estimated scale reliability of

\footnotetext{
${ }^{3}$ It is possible that our disorder measure is picking up some of the same incidents as our count of recorded crime, with both including a measure of the amount of vandalism in the area. However, police recorded crime figures are restricted to those incidents that result in some cost to an individual, whereas our interviewer rating provides a more general assessment of the local area, therefore the overlap is likely to be minimal. A second measure of disorder that omitted the extent of vandalism was also tested, with no substantive differences in results evident.

${ }^{4}$ Interviewers were not asked to rate the extent of social disorder in the surrounding area, however we expect the incidence of these forms of disorder to be minimal across neighbourhoods (in their study of Chicago neighbourhoods Sampson and Raudenbush, 1999, observed street drug dealing in only 12 of the 15,111 sampled street blocks, with similarly low counts of other social disorders).
} 
0.93. ${ }^{5}$ As with our measure of the neighborhood crime rate, this measure of disorder has the strong advantage that its measurement is exogenous to the measurement of fear of crime. It is not, therefore, possible for any association between disorder and fear that we might observe using this approach to be explained in terms of respondents aligning their assessments of disorder, either consciously or unconsciously, with their expressed level of fear.

Variables representing the social and organizational structure of neighborhoods are derived from the 2001 census of England and Wales. This yields information covering: unemployment; occupations; population structure; car ownership; housing; occupancy details and tenure; and in and out migration. These are supplemented by administrative data from the neighborhood statistics division of ONS detailing: the proportion of the population on income support; and the amount of land classified as domestic, non-domestic and green-space (summary details available from corresponding author on request). Amongst these neighborhood measures there is a high degree of collinearity, reflecting their status as multiple indicators of a few principal dimensions of neighborhoods. This is a common problem with the use of neighborhood level data which can lead to estimation problems, inflated standard errors and unstable results (Johnston et al., 2004).

To deal with this, we adopt a 'factorial ecology' approach to generate a series of structural indices that summarize the strong correlations evident amongst these measures (Rees, 1971). This uses a principal components extraction with an orthogonal rotation procedure to retain all components which account for more variance than the average neighborhood variable (Kaiser, 1970). ${ }^{6}$ Five components were extracted, accounting for $82 \%$ of the total variation in the 21 items included in the analysis (table 1 ). The component structure is similar to that reported in previous factorial ecology studies in the UK (Johnston et al., 2004;

\footnotetext{
${ }^{5}$ Calculated following the methodology of Goldstein et al., 2008, $\rho_{\mathrm{T}}=\mathrm{n} \sigma_{\mathrm{u}}{ }^{2} /\left(\mathrm{n} \sigma_{\mathrm{u}}{ }^{2}+\sigma_{\mathrm{e}}{ }^{2}\right)$, based on an average of 20 interviewer evaluations per neighborhood cluster.

${ }^{6}$ An oblique rotation was also examined, however all extracted factors were uncorrelated, and substantively identical to the factors using the orthogonal procedure.
} 
Propper et al., 2005), and falls largely in line with the classifications identified in social disorganization theory. They also closely match the contextual measures used in studies by Sampson and colleagues (Morenoff, Sampson and Raudenbush, 2001; Sampson and Raudenbush, 1999; Sampson, Raudenbush and Earls, 1997). Following previous studies, these components have been labeled as measures of socioeconomic disadvantage, urbanicity, population mobility, neighborhood age profile, and housing profile. We also include a measure of ethnic diversity, derived from the herfindahl index (Hirschman, 1964) which yields the probability of two randomly selected individuals from the same locality being of different ethnic origin (White, Black, Asian, or Other). ${ }^{7}$ Following existing research on neighborhoods, we expect structural factors which inhibit social cohesion, particularly socio-economic disadvantage, urbanicity, population mobility and ethnic diversity, to be associated with higher levels of fear.

\section{Table 1 about here}

A range of individual level covariates is included to control for compositional differences between neighborhoods and to enable an evaluation of the extent to which neighborhood characteristics interact with individual-level causes of fear. These have been selected on the basis of the findings of previous investigations, and cover the influences of vulnerability characteristics (age, gender, ethnicity, physical illness), direct victimization experience (personal and household victimization in the last 12 months), media consumption (newspaper readership), social class, marital status, and educational level. Including these covariates in the individual level model means that our estimates of neighborhood level effects provide some adjustment for the sorts of selection mechanisms that lead to an uneven distribution of individual level characteristics - which are themselves correlated with fear of crime - across neighborhoods. As with any such adjustment strategy, however, the validity of our inferences depends on

\footnotetext{
${ }^{7}$ The full ethnic classification was not used due to the large number of empty cells when constructing the index at MSOA level.
} 
having included all relevant control variables, an assumption for which a satisfactory test is not available (Morgan and Winship, 2007). We also include dummy variables for survey year to control for macro level changes in fear over the three years of the survey examined

\section{ANALYSIS}

To test our four hypotheses we estimate a series of increasingly complex multilevel models. First we estimate a 'random intercept' model, including only our individual level fixed effects (model I). This provides us with an initial indication of the extent to which unobserved neighborhood characteristics contribute to variations in fear of crime, acting as a baseline comparison for subsequent models. Assessing the relative contribution of neighborhood differences whilst simultaneously controlling for individual fixed effects provides some protection against the uneven sample composition within each neighborhood.

In models II, III, and IV we then introduce our measures of recorded crime, visible signs of neighborhood disorder, and neighborhood social and organizational structures, respectively. These models provide an estimate of the unconditional association of each of our neighborhood characteristics with individual levels of fear. These characteristics are then included simultaneously in model $\mathrm{V}$, giving us a test of hypotheses $\mathrm{H} 1$ to H3. In model VI we allow all individual level associations to vary across neighborhoods, with each 'random coefficient' estimated separately, before estimating all significant coefficients simultaneously (Hox, 2002). Significant random coefficients indicate that the magnitude of the individual relationship with fear varies significantly across the sample of neighborhoods, providing a test of hypothesis H4. Finally, in model VII, we include interaction terms between each neighborhood structural characteristic and the individual level variables for which a significant random coefficient was detected in model VI. This enables us to identify the neighborhood characteristics which moderate individual relationships with fear, linking contextual processes back to the individual level explanations 
posited within early research to describe how the effects of previous victimization experience and greater levels of vulnerability are moderated by the social structure of the local environment. ${ }^{8}$

The full model is denoted in equation $1 .^{9}$

$\mathrm{y}_{\mathrm{ijk}}=\beta_{0 \mathrm{ijk}}+\beta_{1 \mathrm{j}} \mathrm{x}_{1 \mathrm{ijk}}+\alpha_{1} \mathrm{~W}_{1 \mathrm{jk}}+\alpha_{2} \mathrm{~W}_{1 \mathrm{jk}} \mathrm{x}_{1 \mathrm{ijk}}$

$\beta_{0 \mathrm{ijk}}=\beta_{0}+\mathrm{v}_{0 \mathrm{k}}+\mathrm{u}_{0 \mathrm{jk}}+\mathrm{e}_{0 \mathrm{ijk}}$

$\beta_{1 \mathrm{j}}=\beta_{1}+\mathrm{u}_{1 \mathrm{jk}}$

Here $\mathrm{y}_{\mathrm{ijk}}$ is the level of fear for the $i^{\text {th }}$ individual in the $j^{\text {th }}$ neighborhood within the $k^{\text {th }}$ CDRP, $\beta_{0 \mathrm{ijk}}$ is the intercept, and $\beta_{1 \mathrm{j}}$ is the regression coefficient for individual $i$ in neighborhood $j$ and CDRP $k$ for the individual level covariate $\mathrm{x}_{1 \mathrm{jjk}}$. $\alpha_{1}$ is the regression coefficient for the neighborhood level covariate, $\mathrm{w}_{1 \mathrm{jk}}$, in neighborhood $j$ and CDRP $k$, and $\alpha_{2}$ is the cross level interaction between the individual covariate, $\mathrm{x}_{1 \mathrm{ijk}}$, and the neighborhood covariate, $\mathrm{w}_{1 \mathrm{jk}}$. The second and third lines of equation 1 define the random part of the model: $\mathrm{v}_{0 \mathrm{k}}$ is the CDRP level error for the random intercept; $\mathrm{u}_{0 \mathrm{jk}}$ is the neighborhood level error for the random intercept; and $\mathrm{e}_{0 \mathrm{jik}}$ is a person specific error. $\mathrm{u}_{1 \mathrm{jk}}$ is the neighborhood level error for the regression coefficient $\beta_{1}$, indicating that the individual coefficient is allowed to vary across neighborhoods. ${ }^{10}$ These random effects are assumed to have means of zero and normally distributed variances denoted, $\sigma_{\mathrm{v} 0}{ }^{2}, \sigma_{\mathrm{u} 0}{ }^{2}$, $\sigma_{\mathrm{e} 0}{ }^{2}$, and ${\sigma_{\mathrm{u} 1}}^{2}$ respectively, as well as the covariance between the random intercept and the random coefficient, $\sigma_{\mathrm{u} 0 \mathrm{u} 1}$ (all other covariance terms have been constrained to 0 , reflecting the lack of theoretical justification for their inclusion). All right-hand side variables are centered at their mean values to allow for straightforward interpretation of the random part of the model.

\footnotetext{
${ }^{8}$ Buck (2001) notes the potential existence of non-linear neighborhood effects, and advocates the inclusion of polynomial terms and interactions within contextual models. These were tested for in the current analysis, however none were identified.

${ }^{9}$ A detailed explanation of multilevel modeling is given in Goldstein, (2003).

${ }^{10}$ We also assessed whether level 1 fixed effects varied across CDRP, but no significant variation was evident.
} 


\section{RESULTS}

In line with existing research, model I (table 2) shows that fear is significantly higher amongst women, people with poor health, those identified as more socio-economically disadvantaged, those with recent experience of household or personal victimization (repeat victims are identified as even more fearful of crime), and readers of newspapers that devote a larger proportion of space to the reporting of violent crimes. More importantly for our purposes, the model also confirms that variations in fear cannot be explained by reference to individual characteristics alone, with neighborhoods and CDRP areas accounting jointly for approximately $8 \%$ of the total variability in fear. Of this variation, $50 \%$ has been classified as the result of differences between the CDRP that neighborhoods are grouped within, suggesting there is a substantial similarity amongst neighborhoods from within the same CDRP area. The variation partitioned between CDRP reflects a high degree of similarity amongst neighborhoods within close proximity to one another but also suggests the existence of causal mechanisms operating at a larger spatial scale than the neighborhood level, such as police force operational structure and effectiveness. Unfortunately, the lack of robust and complete data currently available at the CDRP level means that we are not able at this juncture to probe further into the nature and functioning of these mechanisms.

The joint contribution of neighborhoods and CDRP is smaller than has been identified in previous studies of contextual influences on fear of crime, where the unexplained geographical unit contribution has been estimated within a range of $12 \%$ to $18 \%$ (Perkins and Taylor, 1996; Robinson, 2003; Snell, 2001; Taylor, 2001; Wyant, 2008). That our analysis yields a lower neighborhood level variance component than previous studies does not lead us to question the validity of our findings, for there are a number of plausible reasons why our variance estimates should be smaller than previous studies. First, we have included a large and varied set of individual and neighborhood level covariates which has not always been true of previous studies; our 'intercept only' model yields a variance component of $10 \%$, so part of the difference may simply be that our explanatory variables are doing a better job of accounting for the total neighborhood level variability. Second, our lower neighborhood level variance estimate might also 
reflect the small spatial scale of our neighborhood units and our use of the full national distribution of neighborhoods. And, third, the difference might also reflect our choice of outcome measure, with many existing studies using questions that tap different dimensions of fear or that refer directly to the 'local area' or 'neighborhood' in the question wording.

\section{Table 2 about here}

Models II-IV (table 3) provide strong initial support for hypotheses H1 to H3, with recorded crime rates, observable signs of disorder, and the social-structural characteristics of the neighborhood all significantly predictive of crime-related fear. In model II residents living in neighborhoods with higher levels of recorded crime report significantly higher levels of fear than residents with similar individual characteristics living in low crime rate neighborhoods. Model III incorporates interviewer assessments of visible signs of physical disorder within the neighborhood to show that residents living in neighborhoods with higher frequencies of visible signs of disorder report higher levels of fear. Finally, model IV shows that indicators of weak social and organizational neighborhood structures are also predictive of fear of crime, with higher levels of fear expressed by people living in more ethnically diverse, socioeconomically disadvantaged, and urban neighborhoods. Fear is also higher in areas with a younger neighborhood age structure and more population mobility, although these effects are considerably weaker.

The inclusion of these neighborhood level variables leads to notable reductions in the residual variance partitioned between neighborhoods within CDRP, reducing the unexplained variance by $19 \%$, $14 \%$, and $30 \%$ for models II, III and IV respectively. ${ }^{11}$ The explained contextual-level variance is primarily between CDRPs, confirming that a considerable amount of the residual variation that we had initially attributed to potential mechanisms operating at the level of CDRP actually reflects differences in

\footnotetext{
${ }^{11}$ This is calculated by taking the proportional reduction in residual CDRP + neighborhood variance. For example, considering the explanatory power of recorded crime we have: $(0.073-0.059) / 0.073=0.19$.
} 
the composition of neighborhoods within each CDRP cluster. Importantly, by retaining CDRP as a higher level of spatial clustering in our model, our neighborhood level estimates have been properly adjusted for these within-CDRP dependencies.

\section{Table 3 about here}

Model V incorporates all three neighborhood mechanisms simultaneously, confirming hypotheses H1 to H3. The crime rate, the extent of visible disorder, and the social and organizational structure of the neighborhood all exert direct and independent effects on the expressed fear of otherwise similar people living in otherwise similar neighborhoods. In assessing the substantive relevance of these coefficients, we should not, of course, be over-reliant on tests of statistical significance, particularly when the sample size is so large. Yet, given the essentially arbitrary nature of the scale of our dependent variable, it is difficult to provide effect size estimates that have any intuitive appeal, in terms of magnitude. For this reason, we take as our reference point the difference in expressed fear from model $\mathrm{V}$ between an individual who has been a victim of personal crime once and an individual who has not been a victim of personal crime (0.22). Comparing the estimated level of fear of crime for a resident living in a low crime rate neighborhood (bottom $2.5 \%$ of the distribution) with a resident of a high crime-rate neighborhood (top $2.5 \%$ of the distribution $)^{12}$ the magnitude of the difference in fear $(0.19)$ is very similar to that between a victim and a non-victim of personal crime. For visual signs of disorder, the same comparison yields a slightly lower but still comparable difference in fear of 0.11 between a resident from a neighborhood in the bottom $2.5 \%$ of the distribution and the top $2.5 \%$ on our measure of visible signs of disorder. Turning to our structural variables, there is a difference in fear of .07 between a resident living in a neighborhood with a high level of disadvantage (the top $2.5 \%$ of the distribution) and a resident from a neighborhood with a low level of disadvantage (the bottom $2.5 \%$ of the distribution). For ethnic diversity there is a

\footnotetext{
${ }^{12}$ But with the same characteristics on the individual and area level fixed effects in Model V.
} 
difference in fear of 0.16 between a resident from a neighborhood defined as ethnically homogenous (a score on the herfindahl index of 0 ), and a resident from the most ethnically diverse neighborhood (with a score of 0.71 ). In sum, the effects of these variables are not just of statistical significance but have a psychological impact of a similar order of magnitude to being the victim of a crime against the person.

Taken together, the variables representing the three neighborhood mechanisms account for $34 \%$ of the variation in fear between neighborhoods within CDRP. Thus, their joint effect is only marginally greater than is evident for any of them considered in isolation. This is particularly true of the socialstructural variables which account for $30 \%$ of the contextual variability on their own. A clear implication here is that there is a good deal of causal dependency between these variables. It is likely, for instance, that social-structural characteristics influence both the crime rate and the level of physical disorder in a neighborhood, that the level of disorder also influences the crime rate, and that the crime rate itself feeds back, over time, to produce and reproduce weaker social-structural characteristics (Sampson and Raudenbush, 2001). It is not our goal in this paper to identify the distinct indirect and total effects of each of the three proposed mechanisms. Indeed, we believe that attempting to do so would push our observational data beyond its inferential limits (Morgan and Winship, 2007). Instead, our approach is to focus on the more tractable strategy of identifying the direct and independent effects of each mechanism. In adopting this pragmatic approach, however, it is essential to note that we are almost certainly oversimplifying the complexity of the true causal system and under-estimating the total effect of each proposed mechanism.

Model VI (table 4) allows the individual-level coefficients to have a random component at the neighborhood level (coefficients with significant variability are underlined). This confirms hypothesis $\mathrm{H} 4$, in showing that several of the observed individual-level correlates of fear are moderated by the neighborhood in which an individual lives, with substantial differences in the size of some level 1 fixed effects across the sample of neighborhoods.

\section{Table 4 about here}


Table 5 illustrates how these coefficient estimates vary across neighborhoods, summarizing the range of values each coefficient takes across the middle 95\% of neighborhoods (Snijders and Bosker, 1999: 85). ${ }^{13}$

\section{Table 5 about here}

These findings clearly demonstrate that many of the differences in fear that have been identified between different types of individual are, in fact, conditional on characteristics of the local neighborhood, with the effect of victimization experience, gender, ethnicity, health and length of residence all varying substantially across neighborhoods. The net result is that, in some neighborhoods, there will be larger than average differences in fear between these groups, whilst in others these differences will be more modest, or even operate in the opposite direction to the population average. Particularly notable in this regard is the fact that, while ethnic minority residents are identified as being more fearful than whites at the national level, this difference is far from constant across neighborhoods. Minority ethnic group residents living in some neighborhoods are significantly more fearful than the population average estimate, while in other neighborhoods the ethnic group difference actually reverses, with whites identified as the most fearful group. Similarly, there is considerable variability in the effect of having been a victim of personal crime in the last year on fear across neighborhoods, with a large difference between victims and non-victims in some neighborhoods, but comparatively little difference in others.

Having found considerable support for the moderating effect of neighborhoods, our final step is to examine which neighborhood characteristics can explain this variability. To do this, model VII (table 4) includes eight 'cross-level' interactions between individual and neighborhood level variables. Our findings here show that all three neighborhood mechanisms - social structure, recorded crime, and visible signs of disorder - significantly moderate the effects of individual level predictors of crime. From a policy perspective, the interaction between the neighborhood crime rate and the effect of a resident's own

\footnotetext{
${ }^{13}$ Estimates of the variance and covariance terms are available on request to the author.
} 
victimization history is particularly interesting, with a heightened negative effect of the neighborhood crime rate on fear amongst those who have been a victim of personal crime once in the last year, compared to both non-victims and repeat victims (figure 1). This suggests that, following a first victimization experience, the neighborhood crime rate becomes of particular salience. Those victims living in low crime rate areas perhaps view the experience as an isolated and unusual incident. In contrast, a first victimization experience for a resident of a high crime neighborhood may serve to 'bring home' the real and present danger in a particularly vivid way. The same interaction effect is not evident for those who have experienced repeat-victimization. Because this group already have so much higher levels of fear than both 'one-time' victims and non-victims, it seems likely that the contextual effect of the neighborhood crime rate for this group is drowned out by the power of their own experiential history.

\section{Figure 1 about here}

We also find that neighborhood ethnic diversity moderates differences in fear of crime between ethnic groups (figure 2). White people living in more ethnically diverse neighborhoods have higher levels of fear than whites living in less diverse neighborhoods, with similar (albeit smaller) increases in fear in more diverse neighborhoods when considering Asian and mixed-origin residents. However, for blacks, living in more ethnically diverse neighborhoods is associated with significantly lower levels of fear, due perhaps to a reduced sense of vulnerability that is likely to arise from being a member of a (highly visible) ethnic group in an otherwise homogenous neighborhood. ${ }^{14}$ The lack of a significant interaction for Asian and

\footnotetext{
${ }^{14}$ It is plausible that the lower fear amongst Black residents in diverse neighborhoods is actually a reflection of the increased proportion of non-white residents in these areas, rather than diversity per se. To test this proposition, the proportion of non-white residents was also included as a contextual effect in the model. This had no material effect on the results presented here, lending confidence to the assertion that this is a reflection of the effect of diversity, not simply the proportion of non-white neighbors in the area. These analyses are available from the corresponding author upon request.
} 
mixed origin residents does not support this interpretation but may reflect the smaller samples of these ethnic groups in our sample, with both groups displaying negative (but non-significant) interaction terms that serve to reduce, but not reverse, the role of diversity.

\section{Figure 2 about here}

Model VII also shows that the effect of length of residence in the neighborhood is different for urban and rural locations. This can be shown graphically by plotting the levels of fear of recently arrived and longterm residents against the level of urbanization of the neighborhood (figure 3). Here we see that, in more rural areas, recently arrived residents are more fearful than long term residents, whilst in more urban areas the pattern is reversed: fear of crime is higher amongst the long-term residents. This patterning is likely to emanate, at least in part, from the differential constraints on residential mobility between urban and rural contexts, with long-term residents in poorer urban and metropolitan neighborhoods less able to move to 'safer' areas if their local area starts to become run-down.

\section{Figure 3 about here}

Finally, the fear of crime of women and people with a longstanding illness is heightened in neighborhoods that contain more visible signs of disorder. Women are also shown to be more fearful of crime in neighborhoods that are identified as more socio-economically disadvantaged, and with a larger population of young people. These findings support the view that the symbolic value of neighborhood characteristics which promote or inhibit collective efficacy and of visible signs of low-level disorder may be greater relevance and informational value for more vulnerable groups in society (Killias, 1990).

\section{DISCUSSION}


A central concern of criminological research during its relatively brief history has been whether and how neighborhoods influence individual perceptions of the risk of criminal victimization. Yet, for primarily methodological reasons, the evidence in support of the contention that 'neighborhoods matter' has been inconsistent and, therefore, unconvincing. Our aim in this paper has been to carefully enunciate the causal mechanisms through which neighborhoods have been proposed to influence fear of crime and to test hypotheses relating to these mechanisms using high quality, nationally representative survey data linked to detailed neighborhood-level information. A key innovation of this research to our understanding of neighborhood effects on fear of crime is our use of independently collected measures of the key predictor and outcome variables in our models. Rather than relying on respondent assessments of neighborhood characteristics, disorder, and crime in the area, we have assembled measures that were collected independently of the survey responses that we use to gauge fear. This means that we are able to discount the kinds of 'cognitive rationalization' explanations that have dogged existing research in this area for so long (Sampson and Raudenbush, 2004). Our analyses confirm that, in the British context, neighborhoods exert independent influences on fear of crime through: 1. the incidence of reported crime; 2. visible signs of low-level disorder; 3. weak social, economic and structural characteristics, and 4. as moderators of individual level causes of fear. These findings have important implications for both criminological theory and for those responsible for the development and implementation of social policy.

Before we turn our attention to the wider relevance of our findings, however, it is important to emphasize once again that, in focusing on the direct and independent effects of these mechanisms in our statistical models, we are very much operating under George Box's imprimatur that 'all models are wrong but some are useful'. It is, of course, highly improbable that these mechanisms operate independently but that, in reality, they interact and feed-back on one another in a highly complex and contingent manner over time (Markowitz et al., 2001). Given the unsuitability of the kind of static observational data at our disposal here for estimating highly complex, dynamic causal models, we have set ourselves the more tractable task of identifying the independent, direct effects of each proposed mechanism. Untangling the 
causal inter-relationships and estimating more complex indirect and total effects will be a useful direction for future research in this area.

A key explanandum of research into the fear of crime to date has been its apparently paradoxical nature - those who are least at risk of victimization are often the most fearful, and vice versa (Hale, 1996). This has lead to suggestions that fear of crime, at least insofar as it is measured in surveys, is not a matter of rational calculation of objective risk but an expression of more general anxieties about perceived neighborhood decline and broader societal atomization (Hollway and Jefferson, 1997). Such a position is, of course, problematic for policy makers who would like to use conventional fear of crime measures in surveys like the BCS as barometers of the public's reaction to reduced (or increased) risk of criminal victimization and, therefore, the efficacy of policy interventions. This has prompted considerable criticism of existing fear measures, which Farrall and Ditton (1999: 56) argue have simply "been reproduced without much thought given to why these questions had been worded in the way that they had been, or to whether these questions were at all appropriate". On the contrary, however, our research has shown that the incidence of recorded crime in a neighborhood is directly related to the level of reported fear, as measured by these questions. In substantive terms, the effect of neighborhood crime rates are not trivial, with a move from the bottom to the top of the distribution (and holding all other variables in the model constant) resulting in an increase in individual level fear equivalent to the effect of a personal victimization experience. It is worth noting that inconsistencies in data collection between police forces, and the incomplete picture these figures offer of less serious offences means that our measure of recorded crime means this measure is likely to contain a high degree of both random and systematic measurement error. This means that we are almost certainly under-estimating the magnitude of its effect on fear. A key conclusion to be drawn from our research, then, is that conventional survey measures of fear of crime are capable of detecting variation in 'rational' responses to objective risks of victimization.

This conclusion is further supported by the observation that the effect of recorded crime at the local level is moderated by an individual's own experience of victimization. Those without a history of victimization are largely unaffected by the local crime rate, while the level of fear expressed by those who 
have themselves been victims of crime is markedly higher in neighborhoods with higher levels of recorded crime. This conditional effect suggests that victims in low-crime areas classify their experiences as isolated incidents (and consequently downplay their informational value), while those who are victimized in a high-crime neighborhood are more likely to interpret their experience as an indicator of the probability of its future recurrence. That this effect is only evident when considering those who have only been victimized once in the last year serves to reinforce this interpretation, with the surrounding crime rate having little meaning as an indicator of 'objective' risk for an individual who has been repeatedly victimized. Again, this pattern of results suggests that these conventional fear of crime questions provide a more valid indicator of public concern about the risk of criminal victimization than their many critics have suggested. On the contrary, our findings imply that these measures can be considered as potentially useful tools for guiding and evaluating policy interventions at both national and local levels.

We have also demonstrated that, over and above the 'objective' risk of victimization, visible signs of neighborhood disorder are highly predictive of expressed fear of crime. Thus, individuals appear to respond to visual cues such as litter, vandalism, and graffiti in the neighborhood as being informative about their risk of victimization. While this cannot be considered an especially novel claim in itself, our research represents an advance on most existing studies due to our use of independently recorded assessments of neighborhood disorder and the comprehensive set of individual and neighborhood level controls employed in our models. This finding supports the view that the emphasis on policing strategies which seek to remove visual signs of 'low-level' disorder is an appropriate way of reducing public anxiety about crime. Additionally, our analyses show that the effect of disorder on expressed fear is moderated by the social and demographic characteristics of individual residents, with more vulnerable groups such as women and those in poor health expressing greater fear in response to signs of neighborhood disorder than their less vulnerable counterparts. This, too, has important implications for policing strategies which are intended to 'reassure' local residents that they are safe, by reducing levels of disorder within local neighborhoods and enhancing community involvement, indicating a need for 
targeted interventions that focus particularly on alleviating the concerns of more vulnerable groups (Innes, 2004).

A final important finding to emerge from our analyses is that the difference in the level of expressed fear of minority and white ethnic groups is moderated by the ethnic diversity of the neighborhood. At the national level, it is clear that black and minority ethnic groups are, in general, more fearful of crime than the white majority (Killias and Clerici, 2000). While our analyses confirm this pattern as a population average, we also find that the magnitude and direction of the difference is strongly conditioned by the characteristics of the neighborhoods in which people live. Indeed, in more ethnically diverse neighborhoods, we find the aggregate pattern is reversed, with black residents feeling significantly less fearful than whites. This problematizes recent assertions from academics, politicians, and media commentators alike about the apparently malign influence of ethnic diversity on civic attitudes and behaviors (Goodhart, 2004; Putnam, 2007). Here too, neighborhoods appear to play an important moderating role and, in doing so, reinforce the point that any effect of neighborhood diversity is likely to depend crucially on the social position of individual residents. 


\section{REFERENCES}

Allen, Jonathan. 2006. Worry about Crime in England and Wales: Findings from the 2003/04 and 2004/05 British

Crime Survey. 15/06. Home Office. Home Office Online Report.

Bankston, William B, Quentin A. L. Jenkins, Cheryl L. Thayer-Doyle, and Carol Y. Thompson. 1987. Fear of Criminal Victimization and Residential Location: The Influence of Perceived Risk. Rural Sociology 32, no. 1:98107.

Bollen, Kenneth, A. 1989. Structural Equations with Latent Variables. New York: Wiley.

Bolling, Keith, Catherine Grant, and Jeri-Lee Donovan. 2008. 2007-08 British Crime Survey (England and Wales): Technical Report Volume 1. London, Home Office. BMRB.

Borooah, Vani K., and Carlos A. Carcach. 1997. Crime and Fear: Evidence from Australia. The British Journal of Criminology 37, no. 4:635-57.

Box, Stephen, Chris Hale, and Glen Andrews. 1988. Explaining Fear of Crime. The British Journal of Criminology 28 , no. $3: 340-56$.

Box, Stephen, Chris Hale, and Pat Pack. 1987. Victimization and Fear of Crime. University of Kent Applied Statistics Research Unit Report to the Home Office.

Brunton-Smith, Ian, and Jonathan Allen. 2010. Measuring Crime. In Social Measurement through Social Surveys: An Applied Approach, eds. Martin Bulmer, Julie Gibbs, and Laura Hyman. Ashgate.

Buck, Nick. 2001. Identifying Neighborhood Effects on Social Exclusion. Urban Studies 38, no. 12:2251-75.

Chaskin, Robert. 1998. Defining Neighborhoods. Paper presented at American Planning Association Casey Symposium on Indicators.

Chiricos, Ted, Sarah Eschholz, and Marc Gertz. 1997. Crime, News and Fear of Crime: Toward an Identification of Audience Effects. Social Problems 44, no. 3:342-57. 
Covington, Jeanette, and Ralph B. Taylor. 1991. Fear of Crime in Urban Residential Neighborhoods: Implications of Between- and Within- Neighborhood Sources for Current Models. The Sociological Quarterly 32, no. 2:231-49.

Farrall, Stephen, Jon Bannister, Jason Ditton, and Elizabeth Gilchrist. 1997. Questioning the Measurement of the Fear of Crime: Findings from a Methodological Study. The British Journal of Criminology 37, no. 4:657-78.

Farrall, Stephen, and Jason Ditton. 1999. Improving the Measurement of Attitudinal Responses: An Example from a Crime Survey. Social Research Methodology 2, no. 1:55-68.

Farrall, Stephen, Jonathan Jackson, and Emily Gray. 2009. Social Order and the Fear of Crime in Contemporary Times. Clarendon Series in Criminology: Oxford University Press.

Ferraro, Kenneth F. 1995. Fear of Crime: Interpreting Victimization Risk. Albany, New York: State University of New York Press.

Ferraro, Kenneth. F., and Randy LaGrange. 1987. The Measurement of Fear of Crime. Sociological Inquiry 57:70101.

Fitzgerald, Robin. 2008. Fear of Crime and the Neighborhood Context in Canadian Cities. Crime and Justice Research Paper Series 85-161-M No.013.

Furstenberg, Frank. 1971. Public Reaction to Crime in the Street. American Scholar 40:601-10.

Gerbner, George, and Larry P. Gross. 1976. Living with Television: the Violence Profile. Journal of Communication 26:172-199.

Girling, Evi, Ian Loader, and Richard Sparks. 2000. Crime and Social Order in Middle England: Questions of Order in and English Town. London: Routledge.

Goldstein, Harvey. 2003. Multilevel Statistical Models. London: Arnold.

Goldstein, Harvey, Daphne Kounali, and Anthony Robinson. 2008. Modelling Measurement Errors and Category Misclassifications in Multilevel Models. Statistical Modelling 8, no. 3:243-61. 
Goodhart, David. 2004. Too Diverse? Prospect 95:30-37.

Hale, Chris. 1996. Fear of Crime: A Review of the Literature. International Review of Victimology 4:79-150.

Hale, Chris, Pat Pack, and John Salked. 1994. The Structural Determinants of Fear of Crime: An Analysis Using Census and Crime Survey Data from England and Wales. International Review of Victimology 3:211-33.

Hirschman, Albert O. 1964. The Paternity of an Index. The American Economic Review 54, no. 5:761.

Hollway, Wendy, and Tony Jefferson. 1997. The Risk Society in an Age of Anxiety: Situating Fear of Crime. British Journal of Sociology 48, no. 2:255-66.

Hough, Mike. 1995. Anxiety about Crime: Findings from the 1994 British Crime Survey. 147. London, Home Office. Home Office Research Study.

Hough, Mike. 2004. Worry About Crime: Mental States or Mental Events. International Journal of Social Research Methodology 7, no. 2:173-76.

Hox, Joop. 2002. Multilevel Analysis: Techniques and Applications. MahWah, New Jersey: Lawrence Erlbaum Associates.

Hunter, Albert. 1978. Symbols of Incivility: Social Disorder and Fear of Crime in Urban Neighborhoods. NCJRS. Reactions to Crime Project.

Innes, Martin. 2004. Signal Crimes and Signal Disorders: Notes on Deviance as Communicative Action. British Journal of Sociology 55, no. 3:335-55.

Jackson, Jonathan. 2004. Experience and Expression: Social and Cultural Significance in the Fear of Crime. The British Journal of Criminology 44:946-66.

Jackson, Jonathan. 2005. Validating New Measures of the Fear of Crime. International Journal of Social Research Methodology 8:297-315.

Jackson, Jonathan. 2006. Introducing Fear of Crime to Risk Research. Risk Analysis 26, no. 1:253-64. 
Jang, Sung Joon, and Byron R. Johnson. 2001. Neighborhood Disorder, Individual Religiosity and Adolescent Use of Illicit Drugs: A Test of Multilevel Hypotheses. Criminology 39, no. 1:109-44.

Johnston, Ron, Kelvyn Jones, Simon Burgess, Carol Propper, Rebecca Sarker, and Anne Bolster. 2004. Scale, Factor Analyses and Neighborhood Effects. Geographical Analysis 36:350-68.

Kaiser, Henry F. 1970. A Second Generation Little Jiffy. Psychometrika 35:401-17.

Kershaw, Chris, Tracy Budd, Graham Kinshott, Joanna Mattinson, Pat Mayhew, and Andy Myhill. 2000. The 2000

British Crime Survey: England and Wales. London, Home Office. Home Office Statistical Bulletin 18/00.

Kershaw, Chris, and Andromachi Tseloni. 2005. Predicting Crime Rates, Fear and Disorder Based on Area Information: Evidence from the 2000 British Crime Survey. International Review of Victimology 12:295-313.

Killias, Martin. 1990. Vulnerability: Towards a Better Understanding of a Key Variable in the Genesis of Fear of Crime. Violence and Victims 5:97-108.

Killias, Martin, and Christian Clerici. 2000. Different Measures of Vulnerability in their Relation to Different Dimensions of Fear of Crime. The British Journal of Criminology 40:437-50.

Krannich, Richard S., E. Helen Berry, and Thomas Greider. 1989. Fear of Crime in Rapidly Changing Rural Communities: A Longitudinal Analysis. Rural Sociology 54, no. 2:195-212.

Lawton, M. Powell, and Silvia Yaffe. 1980. Victimization and Fear of Crime in Elderly Public Housing Tenants. Journal of Gerontology 35:768-79.

Lebel, Alexandre, Robert Pampalon, and Paul Y Villeneuve. 2007. A Multi-Perspective Approach for Defining Neighborhood Units in the Context of Health Inequalities in the Quebec City Region. International Journal of Health Geographics 6, no. 27:1-15.

Lebowitz, Barry. 1975. Age and Fearfulness: Personal and Situational Factors. Journal of Gerontology 30:696-700. 
Lewis, Dan A., and Michael G. Maxfield. 1980. Fear in the Neighborhoods: An Investigation of the Impact of Crime. Journal of Research in Crime and Delinquency 17:160-89.

Lewis, Dan A., and Greta Salem. 1986. Fear of Crime: Incivility and the Production of a Social Problem. New Brunswick: Transaction Books.

Liska, Allen E. 1990. The Significance of Aggregate Dependent Variables and Contextual Independent Variables for Linking Macro and Micro Theories. Social Psychological Quarterly 87: 292-301.

Liska, Allen E., and William Baccaglini. 1990. Feeling Safe by Comparison: Crime in the Newspapers. Social Problems 37, no. 3:360-74.

Liska, Allen E, Joseph J Lawrence, and Andrew Sanchiricom. 1982. Fear of Crime as a Social Fact. Social Forces 60 , no. $3: 760-70$.

Markowitz, Fred E., Paul E. Bellair, Allen E. Liska, and Jianhong Liu. 2001. Extending Social Disorganization Theory: Modeling the Relationships between Cohesion, Disorder, and Fear. Criminology 39:293-320.

McGarrell, Edmund F., Andrew Giacomazzi, and Quint C. Thurman. 1997. Neighborhood Disorder, Integration, and the Fear of Crime. Justice Quarterly 14, no. 3:479-500.

Meredith, William. 1993. Measurement Invariance, Factor Analysis, and Factorial Invariance. Psychometrika $58: 525-43$

Merry, Sally E. 1981. Urban Danger: Life in a Neighborhood of Strangers. Philadelphia. Temple University Press.

Miethe, Terance D., and David Mcdowall. 1993. Contextual Effects in Models of Victimization. Social Forces 71, no. 3:741-59.

Morenoff, Jeffrey D., Robert J. Sampson, and Stephen W. Raudenbush. 2001. Neighborhoodd Inequality, Collective Efficacy, and the Spatial Dynamics of Urban Violence. Criminology 39, no. 3:517-60. 
Morgan, Stephen L., and Christopher Winship. 2007. Counterfactuals and Causal Inference: Methods and Principles for Social Research (Analytical Methods for Social Research). Cambridge University Press.

Noble, Michael, Gemma Wright, Chris Dibben, George Smith, David McLennan, Chelsie Anttila, Helen Barnes, Christina Mokhtar, Stefan Noble, David Avenell, Jo Gardner, Illaria Covizzi, and Myfanwy Lloyd. 2004. The English Indices of Deprivation 2004. London, ODPM Publications.

Oakes, J. Michael. 2004. The (Mis)estimation of Neighborhood Effects: Causal Inference for Practicable Social Epidemiology. Social Science and Medicine 58:1929-52.

Perkins, Douglas D., John W. Meeks, and Ralph B. Taylor. 1992. The Physical Environment of Street Blocks and Resident Perceptions of Crime and Disorder: Implications for Theory and Measurement. Journal of Environmental Psychology 12: 21-34.

Perkins, Douglas D., and Ralph B. Taylor. 1996. Ecological Assessments of Community Disorder: Their Relationship to Fear of Crime and Theoretical Implications. American Journal of Community Psychology 24, no. 1:63-107.

Propper, Carol, Kelvyn Jones, Anne Bolster, Simon Burgess, Ron Johnston, and Rebecca Sarker. 2005. Local Neighborhood and Mental Health: Evidence from the UK. Social Science and Medicine 61:2065-83.

Putnam, Robert D. 2007. E Pluribus Unum: Diversity and Community in the Twenty-first Century. The 2006 Johan Skytte Prize Lecture. Scandinavian Political Studies 30, no. 2:137-74.

Rees, P. H. 1971. Factorial Ecology: An Extended Definition, Survey and Critique of the Field. Economic Geography 47:220-33.

Robinson, Jennifer B., Brian A. Lawton, Ralph B. Taylor, and Douglas D. Perkins. 2003. Multilevel Longitudinal Impacts of Incivilities: Fear of Crime, Expected Safety, and Block Satisfaction. Journal of Quantitative Criminology 19, no. 3:237-74. 
Sampson, Robert J. 2009. Disparity and Diversity in the Contemporary City: Social (Dis)order Revisited. British Journal of Sociology 60, no. 1:1-31.

Sampson, Robert J., Jeffrey D. Morenoff, and Thomas Gannon-Rowley. 2002. Assessing "Neighborhood Effects": Social Processes and New Directions in Research. Annual Review of Sociology 28:443-78.

Sampson, Robert J., and Stephen W. Raudenbush. 1999. Systematic Social Observation of Public Spaces: A New Look at Disorder in Urban Neighborhoods. American Journal of Sociology 105, no. 3:603-51.

Sampson, Robert J., and Stephen W. Raudenbush. 2001. Disorder in Urban Neighborhoods: Does it Lead to Crime? Washington, D.C.: U.S. Department of Justice, National Institute of Justice.

Sampson, Robert J., and Stephen W. Raudenbush. 2004. Seeing Disorder: Neighborhood Stigma and the Social Construction of 'Broken Windows'. Social Psychology Quarterly 67, no. 4:319-42.

Sampson, Robert J., Stephen W. Raudenbush, and Felton Earls. 1997. Neighborhoods and Violent Crime: A Multilevel Study of Collective Efficacy. Science 277:918-24.

Shaw, Clifford R., and Henry D. McKay. 1942. Juvenile Delinquency and Urban Areas. Chicago: University of Chicago Press.

Simmons, Jon, Clarissa Legg, and Rachel Hosking. 2003. National Crime Recording Standards (NCRS): An Analysis of the Impact on Recorded Crime. 31/03. Home Office.

Skogan, Wesley. 1974. The Validity of Official Crime Statistics: An Empirical Investigation. Social Science Quarterly 55:25-38.

Skogan, Wesley. 1987. The Impact of Victimization on Fear. Crime and Delinquency 33:135-54.

Skogan, Wesley. 1990. Disorder and Decline: Crime and the Spiral of Decay in American Neighborhoods. Berkeley: University of California Press. 
Skogan, Wesley. 1996. Measuring what Matters: Crime, Disorder and Fear. In Measuring what Matters: Part One: Measures of Crime, Fear, and Disorder, ed. Thomas V. Brady, Research in Action, a joint publication of the National Institute of Justice and the Office of Community Oriented Policing services. NCJ.

Skogan, Wesley, and Michael G. Maxfield. 1981. Coping with Crime: Individual and Neighborhood Reactions. Beverly Hills, CA: Sage.

Snell, Clete. 2001. Neighborhood Structure, Crime, and Fear of Crime: Testing Bursik and Grasmick's Neighborhood Control Theory. New York: LFB Scholarly Publishing LLC.

Snijders, Tom A. B., and Roel J. Bosker. 1999. Multilevel Analysis: An Introduction to Basic and Advanced Multilevel Modeling. London: Sage.

Taub, Richard. P, D., Garth Taylor, and Janet D. Dunham. 1984. Paths of Neighborhood Change. Chicago: University of Chicago Press.

Taylor, Ralph B. 2001. Breaking Away from Broken Windows: Baltimore Neighborhoods and the Nationwide Fight against Crime, Grime, Fear, and Decline. Boulder, Colorado: Westview Press.

Taylor, Ralph B., and Jeanette Covington. 1993. Community Structural Change and Fear of crime. Social Problems 40, no. 3:374-97.

Taylor, Ralph B., and Margaret Hale. 1986. Testing Alternative Models of Fear of Crime. The Journal of Criminal Law and Criminology 77, no. 1:151-89.

Taylor, Ralph B., Sally Ann Schumaker, and Stephen D. Gottfredson. 1985. Neighborhood-level Links between Physical Features and Local Sentiments: Deterioration, Fear of Crime and Confidence. Journal of Architectural Planning and Research 21:261-75.

Tseloni, Andromachi. 2007. Fear of Crime, Perceived Disorders and Property Crime: A Multivariate Analysis at the Area Level. Crime Prevention Studies 21:163-85.

Vanderveen, Gabry. 2006. Interpreting Fear, Crime, Risk and Unsafety. Boom Juridische Uitgevers. 
Wilcox, Pamela, Neil Quisenberry, and Shayne Jones. 2003. The Built Environment and Community Crime Risk Interpretation. Journal of Research in Crime and Delinquency 40, no. 3:322-45.

Wilcox-Rountree, Pamela. 1998. A Re-examination of the Crime-Fear Linkage. Journal of Research in Crime and Delinquency 35, no. 3:341-72.

Wilcox-Rountree, Pamela, and Kenneth C. Land. 1996. Burglary Victimization, Perceptions of Crime Risk, and Routine Activities: A Multilevel Analysis across Seattle Neighborhoods and Census Tracts. Journal of Research in Crime and Delinquency 33:147-80.

Wilson, James Q., and George L. Kelling. 1982. Broken Windows. Atlantic Monthly. March:29-38.

Wyant, Brian R. 2008. Multilevel Impacts of Perceived Incivilities and Perceptions of Crime Risk on Fear of Crime. Journal of Research in Crime and Delinquency 45:39-64. 
Table 1. Rotated Component Loadings from Factorial Ecology

\begin{tabular}{|c|c|c|c|c|c|}
\hline & Socio-economic & Urbanicity & Population & Age Profile & Housing \\
\hline Neighborhood Measure & disadvantage & & Mobility & & Profile \\
\hline Working population on income support & 0.89 & 0.245 & 0.191 & 0.138 & 0.092 \\
\hline Lone parent families & 0.847 & 0.222 & 0.002 & 0.263 & 0.153 \\
\hline Local authority housing & 0.846 & 0.064 & -0.009 & 0.146 & -0.168 \\
\hline Working population unemployed & 0.843 & 0.293 & 0.173 & 0.118 & 0.125 \\
\hline Non-Car owning households & 0.798 & 0.417 & 0.363 & -0.01 & 0.057 \\
\hline Working in professional/managerial role & -0.787 & 0.002 & 0.153 & 0.146 & -0.368 \\
\hline Owner occupied housing & -0.608 & -0.249 & -0.349 & -0.572 & 0.053 \\
\hline Domestic property & 0.104 & 0.921 & 0.165 & 0.052 & 0.112 \\
\hline Green-space & -0.214 & -0.902 & -0.18 & -0.011 & -0.043 \\
\hline Population density (per square KM) & 0.245 & 0.824 & 0.262 & 0.15 & -0.135 \\
\hline Working in agriculture & -0.126 & -0.663 & -0.006 & -0.183 & -0.03 \\
\hline In migration & -0.074 & 0.102 & 0.916 & 0.069 & 0.071 \\
\hline Out migration & -0.019 & 0.162 & 0.903 & 0.119 & 0.134 \\
\hline Single person, non-pensioner households & 0.355 & 0.364 & 0.743 & 0.134 & -0.092 \\
\hline Commercial property & 0.378 & 0.432 & 0.529 & 0.019 & -0.093 \\
\hline More than 1.5 people per room & 0.428 & 0.472 & 0.507 & 0.197 & -0.326 \\
\hline Resident population over 65 & -0.052 & -0.21 & -0.271 & -0.892 & -0.021 \\
\hline Resident population under 16 & 0.427 & 0.04 & -0.464 & 0.635 & 0.19 \\
\hline Terraced housing & 0.323 & 0.263 & 0.102 & 0.274 & 0.689 \\
\hline Vacant property & 0.319 & -0.118 & 0.485 & -0.173 & 0.53 \\
\hline Flats & 0.453 & 0.359 & 0.489 & 0.008 & -0.524 \\
\hline Mean & 0 & 0 & 0 & 0 & 0 \\
\hline Standard deviation & 1 & 1 & 1 & 1 & 1 \\
\hline Range & $-2.57-4.08$ & $-3.06-3.70$ & $-1.94-8.29$ & $-6.15-3.64$ & $-4.88-5.27$ \\
\hline Eigen Value & 9.3 & 3.3 & 1.9 & 1.4 & 1.3 \\
\hline
\end{tabular}


Table 2. Individual Fear of Criminal Victimization

Model I

Individual level fixed effects

Constant

Gender (Ref: Male)

Female

Age

$\mathrm{Age}^{2}$

Age*Female

Education (Ref: No Qualifications)

GCSE

A level

Degree

Other (foreign)

Ethnicity (Ref: White)

Asian

Black

Mixed/Other

Direct Victimisation (Ref: Non-victim)

Personal Crime (Once)

Personal Crime (Multiple)

Household Crime (Once)

Household Crime (Multiple)

Newspaper Readership (Ref: No Paper)

Tabloid

Broadsheet

Local

NS-SEC (Ref: Professional/Managerial)

Intermediate Occupation

Small Employer

Lower Supervisory Role

Routine or Semi Routine

Never Worked
$0.16(.01)^{* *}$

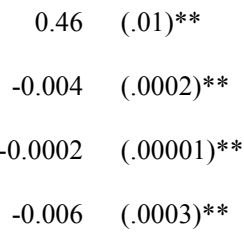

$-0.05 \quad(.01)^{* *}$

$-0.09 \quad(.01)^{* *}$

$-0.18(.01)^{* *}$

$-0.05 \quad(.01)^{* *}$

$0.33(.02)^{* *}$

$0.13(.02)^{* *}$

$0.17(.02)^{* *}$

$0.23(.01)^{* *}$

$0.35(.02)^{* *}$

$0.10(.01)^{* *}$

$0.25(.01)^{* *}$

$0.11 \quad(.01)^{* *}$

$-0.02(.01)^{*}$

$0.09 \quad(.01)^{* *}$

$0.04(.01)^{* *}$

$-0.05 \quad(.01)^{* *}$

$0.04(.01)^{* *}$

$0.08 \quad(.01)^{* *}$

$0.01 \quad(.02)$ 
Student

Marital Status (Ref: Married)

Separated or Divorced

Single

Widowed

Health (Ref: Not Ill)

Non-Limiting Illness

Limiting Illness

Length of Residence

Year (Ref: 2002/03)

2003/04

2004/05

Variance components

CDRP Level

Neighborhood Level

Individual Level

$-2 *$ Loglikelihood

Number of cases

** $P \leq .01 ; * P<.05$.
$0.13(.02)^{* *}$

$-0.07 \quad(.01)^{* *}$

$-0.01 \quad(.01)$

$-0.04 \quad(.01)^{* *}$

$0.10 \quad(.01)^{* *}$

$0.17(.01)^{* *}$

$0.004 \quad(.002)^{*}$

$-0.14(.01)^{* *}$

$-0.14(.01)^{* *}$

$0.037(.003)^{* *}$

$0.036(.002)^{* *}$

$0.812(.004)^{* *}$

272073.8

102,133 
Table 3. Neighborhood Fear of Criminal Victimization

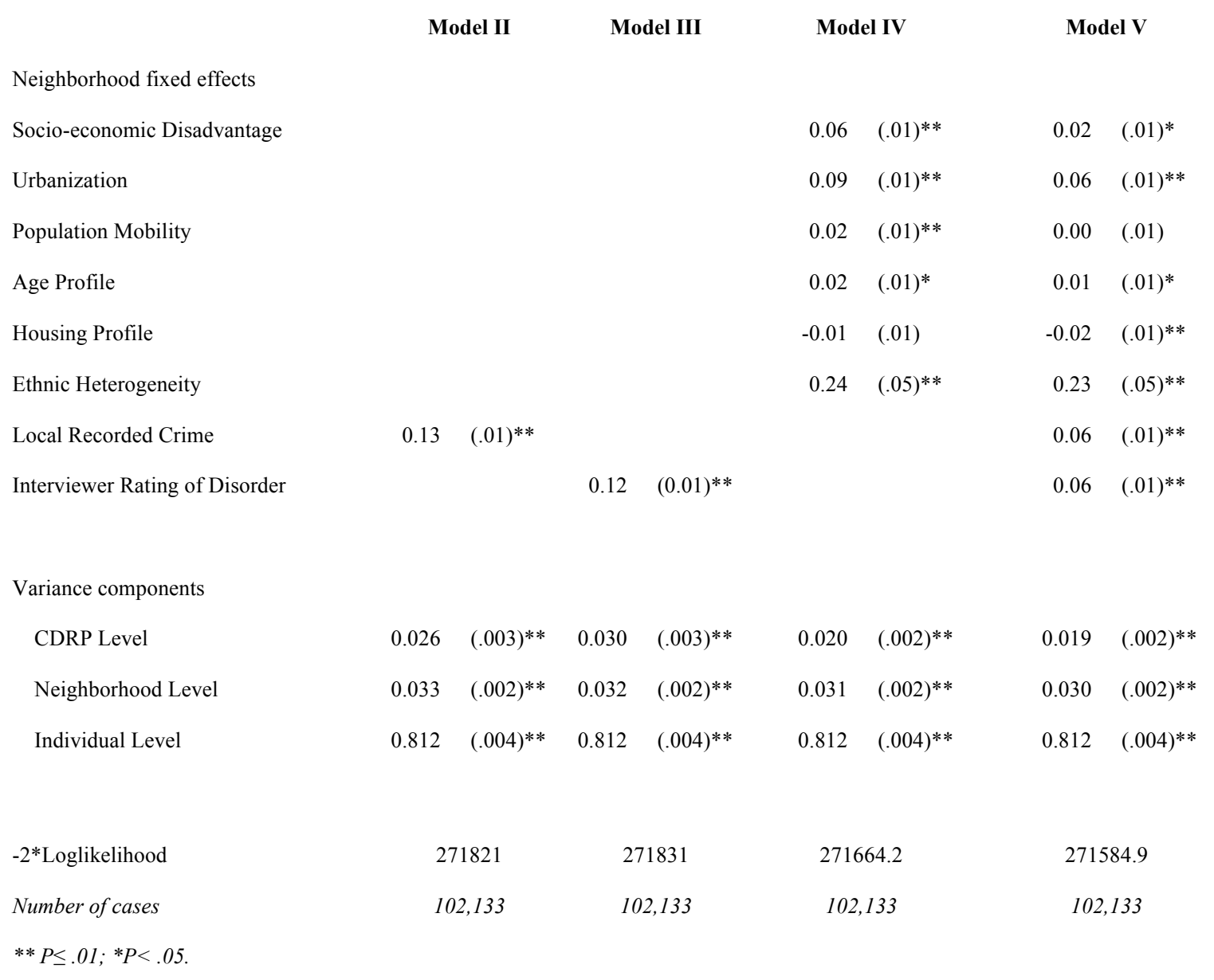


Table 4. Fear of Criminal Victimization

\begin{tabular}{|c|c|c|c|c|}
\hline Individual level fixed effects & \multicolumn{2}{|c|}{ Model VI } & \multicolumn{2}{|c|}{ Model VII } \\
\hline Constant & 0.17 & $(.01)^{* *}$ & 0.17 & $(.01)^{* *}$ \\
\hline \multicolumn{5}{|l|}{ Gender (Ref: Male) } \\
\hline Female & $\underline{0.46}$ & $(.01)^{* *}$ & 0.46 & $(.01)^{* *}$ \\
\hline Age & -0.004 & $(.0002)^{\star *}$ & -0.004 & $(.0002)^{* *}$ \\
\hline $\mathrm{Age}^{2}$ & -0.0002 & $(.00001)^{\star *}$ & -0.0002 & $(.00001)^{\star *}$ \\
\hline Age*Female & -0.006 & $(.0003)^{\star *}$ & -0.006 & $(.0003)^{\star *}$ \\
\hline \multicolumn{5}{|c|}{ Education (Ref: No Qualifications) } \\
\hline GCSE & -0.04 & $(.01)^{* *}$ & -0.04 & $(.01)^{* *}$ \\
\hline A level & -0.08 & $(.01)^{* *}$ & -0.08 & $(.01)^{* *}$ \\
\hline Degree & -0.17 & $(.01)^{* *}$ & -0.17 & $(.01)^{* *}$ \\
\hline Other (foreign) & -0.05 & $(.01)^{* *}$ & -0.05 & $(.01)^{* *}$ \\
\hline \multicolumn{5}{|l|}{ Ethnicity (Ref: White) } \\
\hline Asian & $\underline{0.30}$ & $(.02)^{* *}$ & $\underline{0.34}$ & $(.03)^{\star *}$ \\
\hline Black & $\underline{0.10}$ & $(.03)^{\star *}$ & $\underline{0.19}$ & $(.04)^{\star *}$ \\
\hline Mixed/Other & $\underline{0.15}$ & $(.03)^{* *}$ & $\underline{0.17}$ & $(.03)^{* *}$ \\
\hline \multicolumn{5}{|c|}{ Direct Victimisation (Ref: Non-victim) } \\
\hline Personal Crime (Once) & $\underline{0.23}$ & $(.01)^{* *}$ & 0.22 & $(.01)^{* *}$ \\
\hline Personal Crime (Multiple) & 0.35 & $(.03)^{* *}$ & 0.34 & $(.02)^{* *}$ \\
\hline Household Crime (Once) & 0.10 & $(.01)^{* *}$ & 0.10 & $(.01)^{* *}$ \\
\hline Household Crime (Multiple) & 0.24 & $(.01)^{* *}$ & 0.24 & $(.01)^{* *}$ \\
\hline \multicolumn{5}{|c|}{ Newspaper Readership (Ref: No Paper) } \\
\hline Tabloid & 0.11 & $(.01)^{* *}$ & 0.11 & $(.01)^{* *}$ \\
\hline Broadsheet & -0.01 & $(.01)$ & -0.02 & $(0.01)$ \\
\hline Local & 0.09 & $(.01)^{* *}$ & 0.09 & $(.01)^{* *}$ \\
\hline \multicolumn{5}{|c|}{ NS-SEC (Ref: Professional/Managerial) } \\
\hline Intermediate Occupation & 0.04 & $(.01)^{* *}$ & 0.05 & $(.01)^{* *}$ \\
\hline Small Employer & -0.05 & $(.01)^{* *}$ & -0.05 & $(.01)^{* *}$ \\
\hline Lower Supervisory Role & 0.04 & $(.01)^{* *}$ & 0.04 & $(.01)^{* *}$ \\
\hline Routine or Semi Routine & 0.07 & $(.01)^{* *}$ & 0.07 & $(.01)^{* *}$ \\
\hline Never Worked & 0.00 & $(.02)$ & 0.00 & $(.02)$ \\
\hline
\end{tabular}


Student

Marital Status (Ref: Married)

Separated or Divorced

Single

Widowed

Health (Ref: Not Ill)

Non-Limiting Illness
Limiting Illness
Length of Residence
Year (Ref: 2002/03)
2003/04
2004/05

Neighborhood fixed effects

Socio-economic Disadvantage

*Female

Urbanization

*Length of Residence

Population Mobility

Age Profile

*Female

Housing Profile

*Female

Ethnic Heterogeneity

*Asian

*Black

*Mixed/Other

Local Recorded Crime

*Personal Crime (Once)

*Personal Crime (Multiple)

Interviewer Rating of Disorder

*Female

*Non-limiting Illness

*Limiting Illness
$0.14 \quad(.02)^{* *}$

$0.14(.02)^{* *}$

$-0.08 \quad(.01)^{* *}$

$-0.08 \quad(.01)^{* *}$

$-0.02 \quad(.01)^{*}$

$-0.02 \quad(.01)^{* *}$

$-0.04 \quad(.01)^{* *}$

$-0.04 \quad(.01)^{* *}$

$0.10 \quad(.01)^{* *}$

$0.10 \quad(.01)^{* *}$

$\underline{0.17} \quad \underline{(.01)^{* *}}$

$0.17 \quad(.01)^{* *}$

$\underline{0.004(.002)^{*}}$

$\underline{0.004}(.002)^{*}$

$-0.14 \quad(.01)^{* *}$

$-0.14 \quad(.01)^{* *}$

$-0.13 \quad(.01)^{* *}$

$-0.14 \quad(.01)^{* *}$

$0.02(.01)^{* *}$

$0.02 \quad(.01)^{*}$

$0.04 \quad(.01)^{* *}$

$0.06 \quad(.01)^{* *}$

$0.06 \quad(.01)^{* *}$

$0.01(.002)^{\star *}$

$0.00 \quad(0.01)$

$0.00 \quad(.01)$

$0.01(.005)^{\star *}$

$0.01(.005)^{\star *}$

$0.02 \quad(.01)^{* *}$

$-0.02 \quad(.01)^{* *}$

$-0.02(0.01)^{\star *}$

$0.02(.01)^{* *}$

$0.25(.05)^{\star *}$

$0.27(.05)^{\star *}$

$-0.16 \quad(.11)$

$-0.37(.13)^{\star *}$

$-0.12 \quad(.13)$

$0.05 \quad(.01)^{* *}$

$0.06 \quad(.01)^{* *}$

$0.05 \quad(.02)^{* *}$

$0.01 \quad(.03)$

$0.05 \quad(.01)^{* *}$

$0.06(.01)^{* *}$

$0.03(.01)^{\star *}$

$-0.01 \quad(.03)$

$0.06 \quad(.01)^{* *}$ 
Variance components

CDRP Level

Neighborhood Level

Individual Level

$-2 *$ Loglikelihood

Number of cases

** $P \leq .01 ; * P<.05$.

NOTE: Underlined values represent random coefficients

$\begin{array}{llll}0.017 & (.002)^{* *} & 0.018 & (.002)^{* *} \\ 0.030 & (.002)^{* *} & 0.030 & (.002)^{* *} \\ 0.799 & (.004)^{* *} & 0.800 & (.004)^{* *}\end{array}$

271273

271225.9

102,133

102,133 
Table 5. Variance across Middle $95 \%$ of Neighborhoods

\section{Lower Limit Effect Size Upper Limit}

Individual fixed effects

Gender (Ref: Male)
Female
Ethnicity (Ref: White)
Asian
Black
Mixed/other
Direct Victimization (ref: Non-victim)
Personal Crime (once)
Health (Ref: Not ill)
Limiting Illness
Length of residence

0.31

$-0.41$

$-0.61$

$-0.58$

0.1

$-0.08$

$-0.04$
0.46

0.62

0.3

1.01

0.1

0.81

0.15

0.88

0.22

0.35

0.17

0.43

0.004

0.05 
Figure 1

Fear of Crime by Victimization Experience and Neighborhood Recorded Crime Level

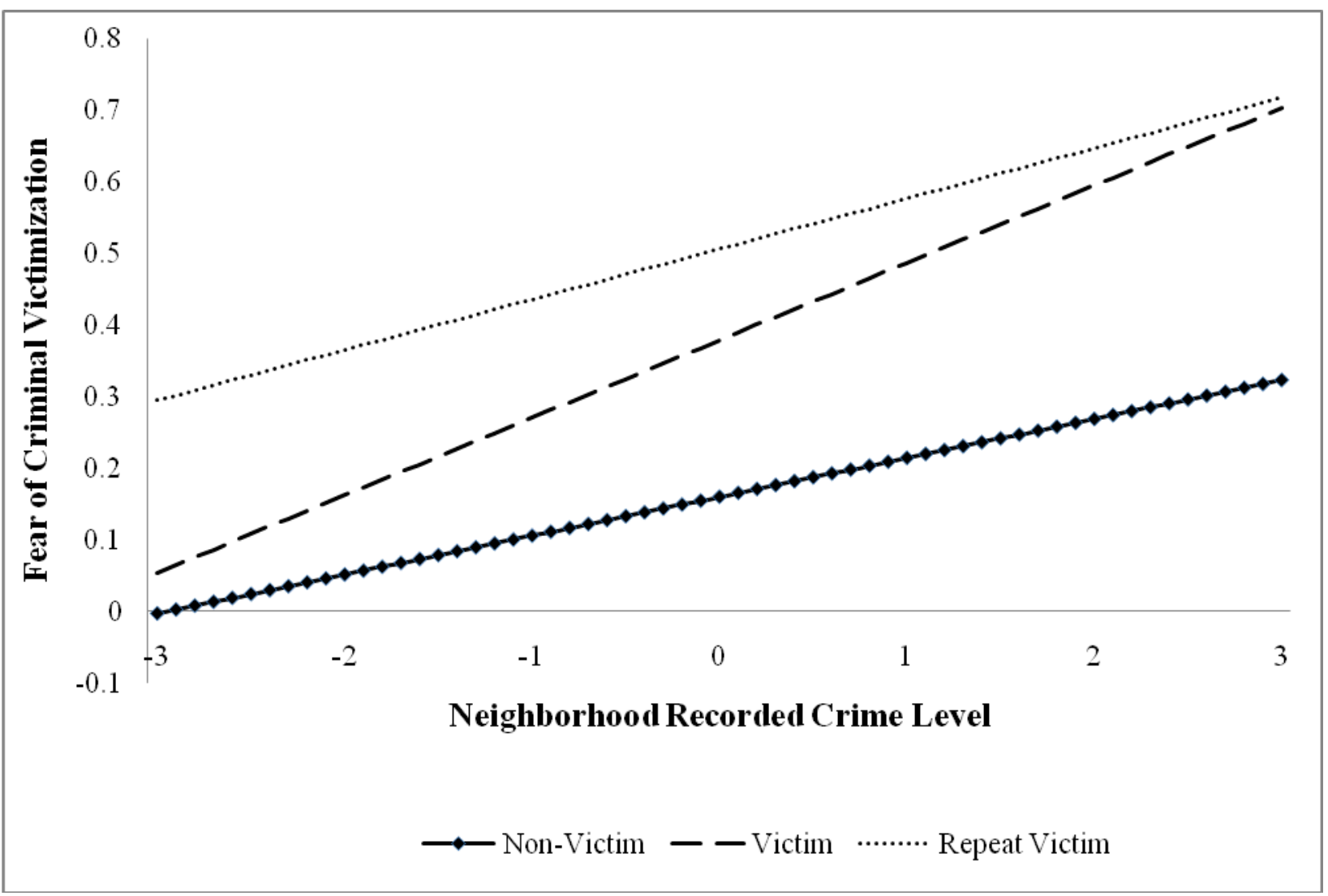


Figure 2

Fear of Crime by Ethnicity and Neighborhood Ethnic Diversity

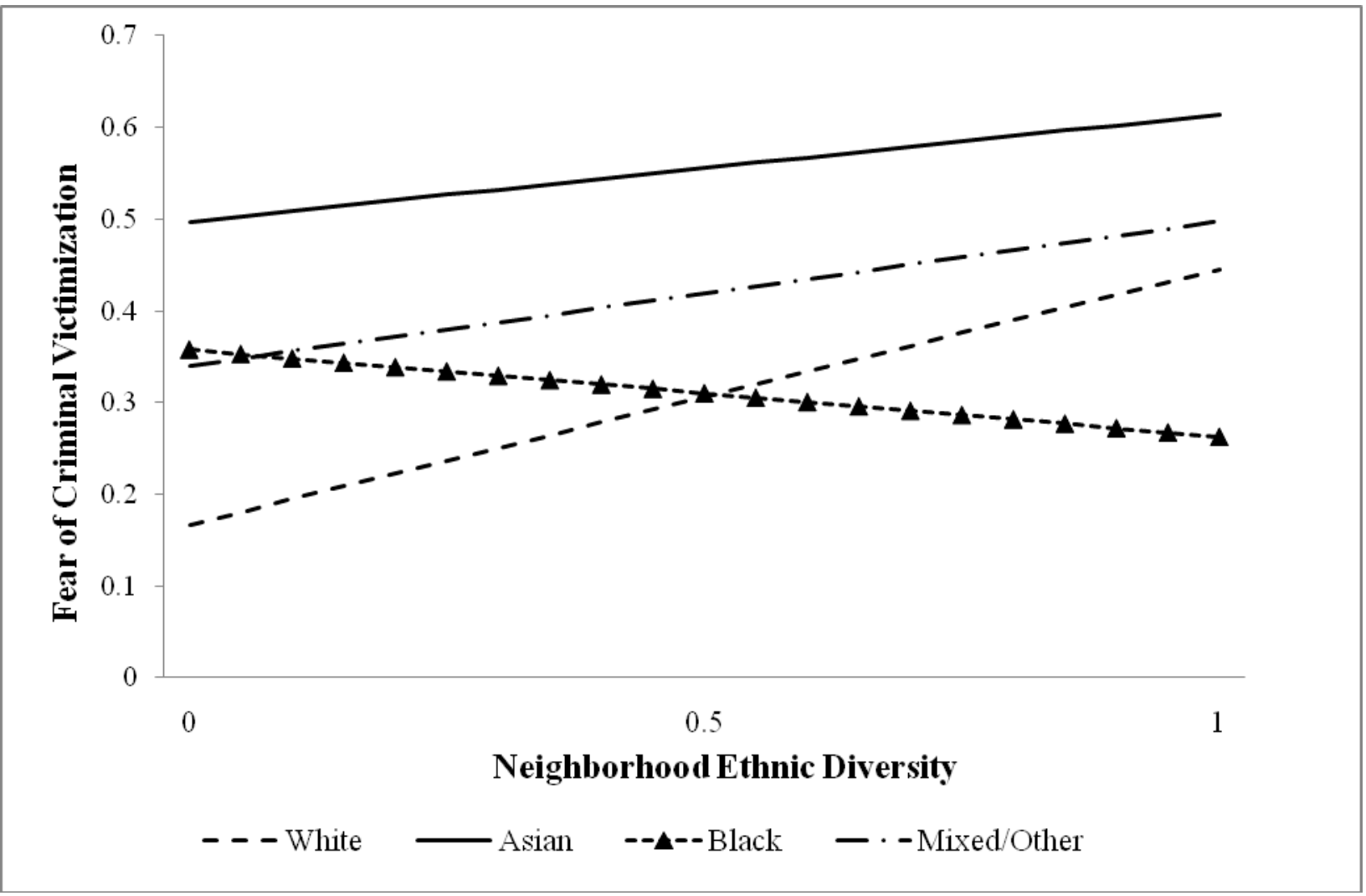

Figure 3 
Fear of Crime by Length of Residence and Neighborhood Urbanicity

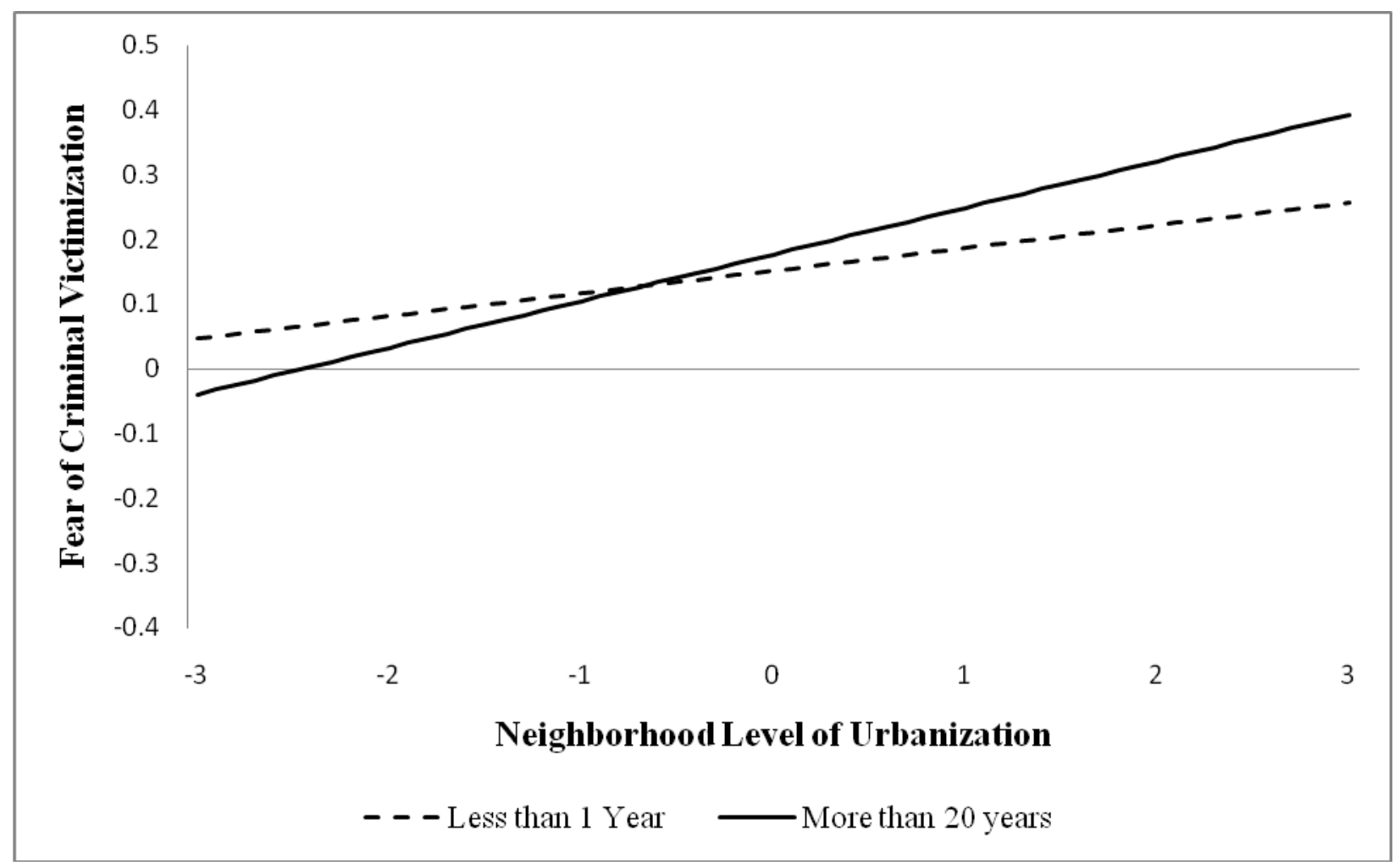

